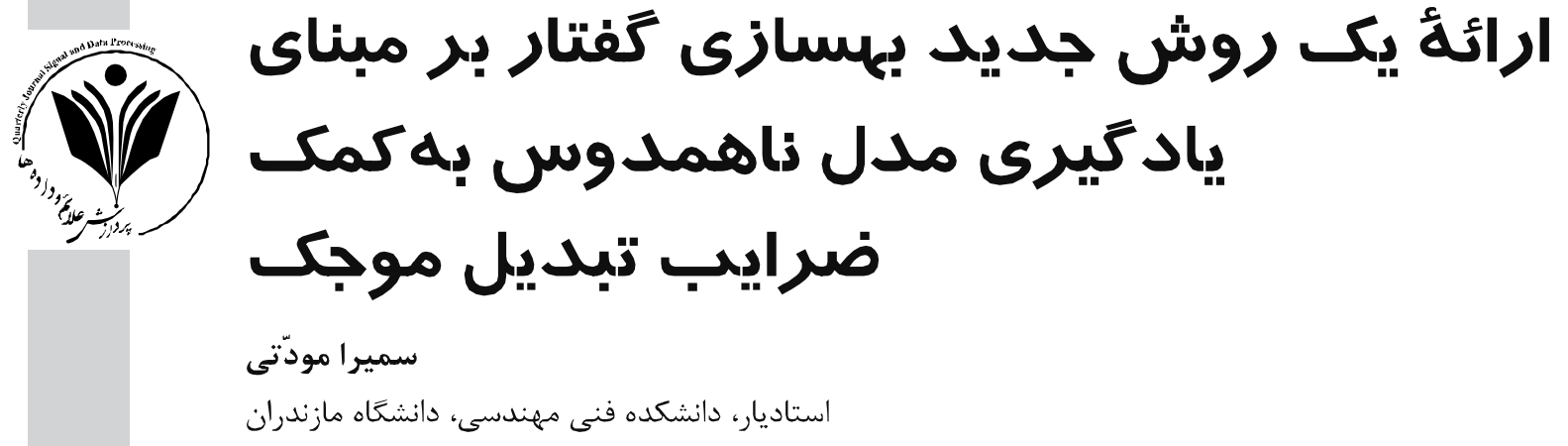

جكکגם

بهسازى كفتتار يكى از زمينه مهاى يركاربرد در يردازش سيكنال است كه در حوزههاى مختلفى مورد استفاده قرار مى مَّيرد. در اين مقاله از

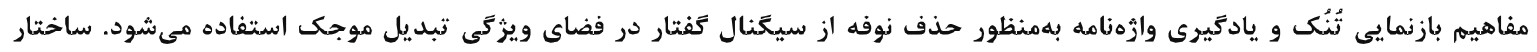

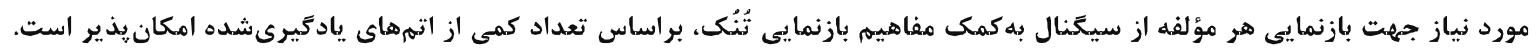

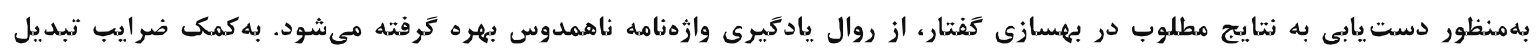

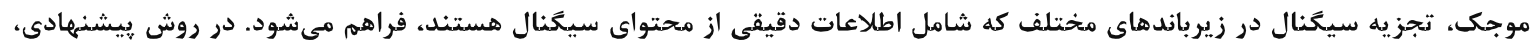

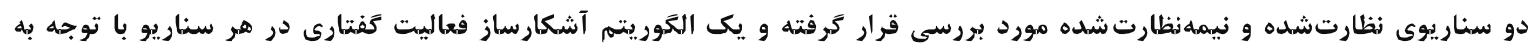

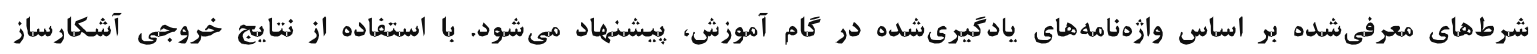

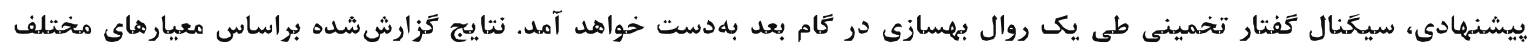

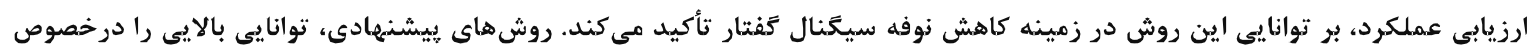
كاهش نوفههاي نايستا به خصوص در مقادير سيعنال به زوفه بر بإيين دارد.

وازَّان كليدى: بهسازى كَفتار، بازنمايى تُنُك، وازمهامه ناهمدوس، تبديل موجك، آشكارساز فعاليت كَفتار.

\title{
A New Method for Speech Enhancement Based on Incoherent Model Learning in Wavelet Transform Domain
}

\author{
Samira Mavaddati \\ Electrical Department, Faculty of Technology and Engineering, \\ University of Mazandaran, Babolsar, Iran
}

\begin{abstract}
Quality of speech signal significantly reduces in the presence of environmental noise signals and leads to the imperfect performance of hearing aid devices, automatic speech recognition systems, and mobile phones. In this paper, the single channel speech enhancement of the corrupted signals by the additive noise signals is considered. A dictionary-based algorithm is proposed to train the speceh and noise models for each subband of wavelet decomposition level based on the coherence criterion. Using the presented learning method, the self-coherence measure between different atoms of each dictionary and mutual coherence between the atoms of speech and noise dictionaries are minimized and lower sparse reconstruction error is yielded. In order to reduce the computation time, a composite dictionary is utilized including only the speech dictionary and one of the noise dictionaries selected corresponding to the noise condition in the test environment. The speech enhancement algorithm is introduced in two scenarios, supervised and semi-supervised situations. In each

* Corresponding author

* نويسندة عهدهار مكاتبات


scenario, a voice activity detector (VAD) scheme is employed based on the energy of sparse coefficient matrices when the observed data is coded over the related dictionary.

The presented VAD algorithms are based on the energy of the coefficient matrices in the sparse representation of the observation data over the specified dictionaries. These speech enhancement schemes are different in the mentioned scenarios. In the proposed supervised scenario, domain adaptation technique is employed to transform a learned noise dictionary into an adapted dictionary according to the noise conditions of the test environment. Using this step, the observed data is sparsely coded with low sparse approximation error based on the current situation of the noisy environment. This technique has a prominent role to obtain better enhancement results particularly when the noise signal has non-stationary characteristics. In the proposed semi-supervised scenario, adaptive thresholding of wavelet coefficients is carried out based on the variance of the estimated noise for each frame in different subbands. These implementations are carried out in two different conditions, the training and test steps, as speaker dependent and speaker independent scenarios.

Also, different measures are applied to evaluate the performance of the presented enhancement procedures. Moreover, a statistical test is used to have a more precise performance evaluation for different considered methods in the various noisy conditions. The experimental results using different measures show that the presented supervised enhancement scheme leads to much better results in comparison with the baseline enhancement methods, learning-based approaches, and earlier wavelet-based algorithms. These results have been obtained for an extensive range of noise types including the structured, unstructured, and periodic noise signals in different SNR values.

Keywords: Speech enhancement, Dictionary learning, Sparse representation, Domain adaptation, Voice activity detector, Wavelet transform

$$
\begin{aligned}
& \text { حوزههاى مختلف صورت گرفته است. بسيارى از تبديلاتى } \\
& \text { كه در زيردازش سيخنال مورد استفاده قرار مى مى ميرند، }
\end{aligned}
$$

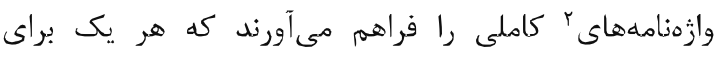

$$
\begin{aligned}
& \text { نمايش دستهاى از سيخنال ها مناسب است. از جمله حوزه يا فيا } \\
& \text { تبديلهاى رايج مى توان به تبديل فوريه، تبديل فوريه زمان } \\
& \text { كوتاه rال } \\
& \text { موجى هام) اشاره كرد. اين نمايشهاى تُنْى، كاربرد } \\
& \text { زيادى در زمينههاى مختلف همجون جداسازى منابع، نمايش }
\end{aligned}
$$

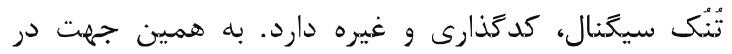

$$
\begin{aligned}
& \text { سالهاى اخير تلاشهاى زيادى براى ارائه نمايشهاى تُنُك } \\
& \text { اين سيخنال ها صورت كرفته است. فضاى ويزَّى در مراجع } \\
& \text { معرفى شده حوزه بهسازى كفتار بهطور عمده تاكنون شامل }
\end{aligned}
$$

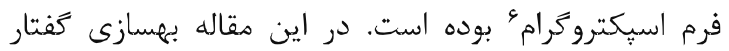

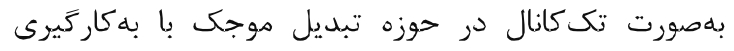

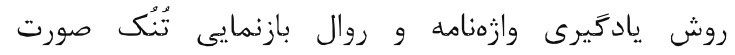

$$
\begin{aligned}
& \text { مى يذيرد و از ضرايب حاصل از آن در سطح تجزيه موردنظر }
\end{aligned}
$$

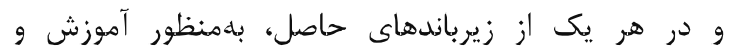

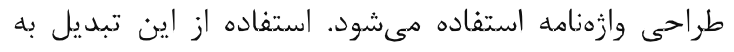

$$
\begin{aligned}
& \text { جند دليل عمده مورد توجه قرار گَرفته است: اين تبديل }
\end{aligned}
$$

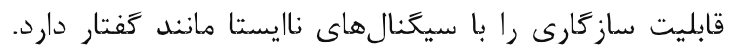

$$
\begin{aligned}
& \text { باند فركانسى سيخنال ورودى جهت مدل كردن ويثزى }
\end{aligned}
$$

${ }^{2}$ Dictionary

${ }^{3}$ Short Time Fourier Transform

${ }^{4}$ Discrete Cosine Transform

${ }^{5}$ Discrete wavelet Transform

${ }^{6}$ Spectrogram dod مق - 1

$$
\text { بهسازى كفتار يكى از زمينههاى مورد علاقئ يثوهش }
$$

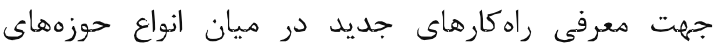$$
\text { يردازش سيخنال است. انواع نوفئه محيطى مى توانند بهصورت }
$$$$
\text { جدى كيفيت و قابليت فهم سيخنال كفتار را با مشكل مواجه }
$$$$
\text { كنند. دسته روشهاى رايه بههنظور بهسازى كفتار ارائهشده }
$$$$
\text { تاكنون شاهل الخوريتمهاى مبتنى بر تفاضل طيفى، طراحى }
$$

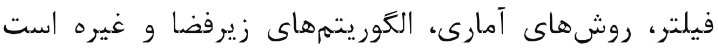

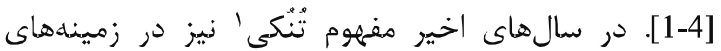$$
\text { مختلف يردازش سيكنال مورد توجه قرار كرفته است. اين }
$$

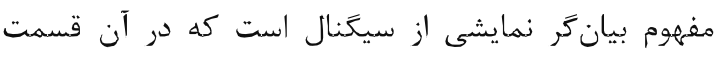

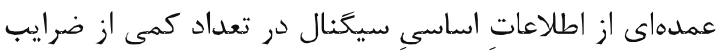

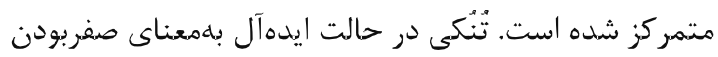

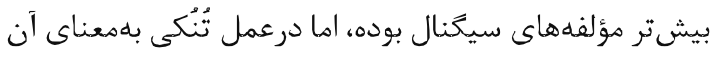

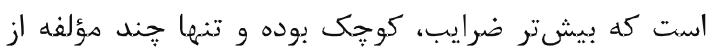

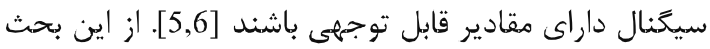$$
\text { در شاخههاى مختلف علوم مهندسى مانند يردازش سيخنال }
$$

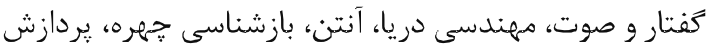

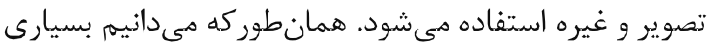

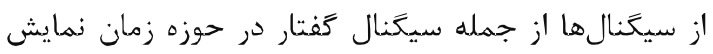

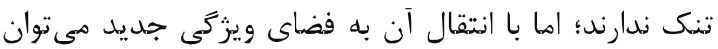

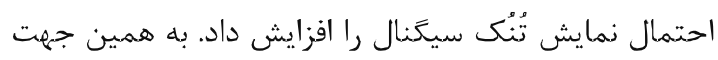$$
\text { تلاشهاى زيادى در راستاى نمايش تُنُك اين سيكنال ها در }
$$

${ }^{1}$ Sparsity 
روش بيشنهمادى در دو سناريوى نظارتشده V

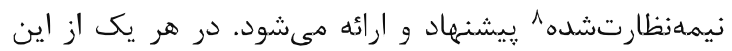
روال ها از آشكارسازى فعاليت كفتارى دقيقى بهمنظور تعيين

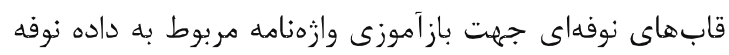

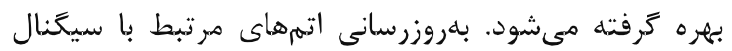

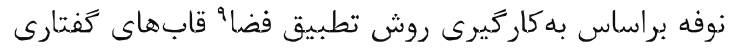

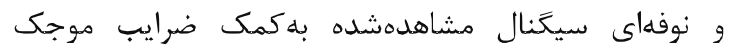

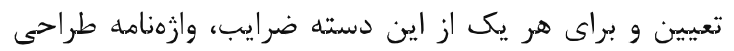

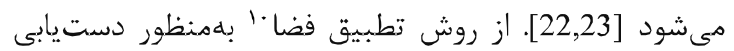
به وازمنامه متناسب با محيط آزمايش و شرايط نوفهاى آن آن

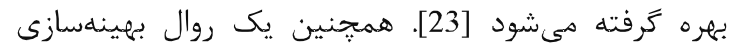

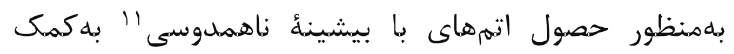

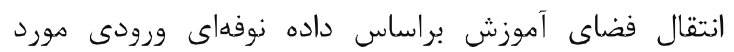
استفاده قرار مى كيرد.

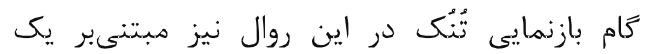

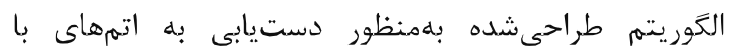
بيشترين همدوسى نسبت به قابهاى داده درنظركرفتهشيده

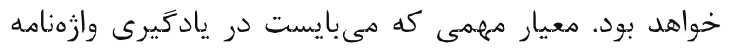

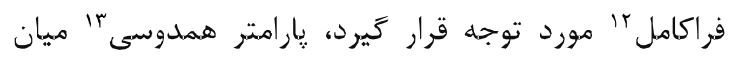
اتمها يا ستونهاى وازمنامه است. كوجكتربودن اين معيار بيانكر اين مسأله است كه هر اتم مستقل از ساير اتمها در

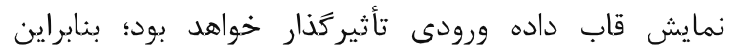
بهكمك اتمهاى آموزشديده تا حد ممكن مستقل، كمترين خطاى تقريب در زمايش تُنْك سيخنال تصوير بهدست مى آيد.

در بخش دوم اين مقاله مسأله حذف نوفه از سيكنال

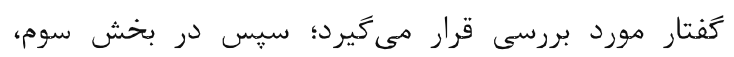

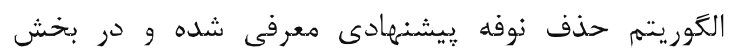
جهارم نتايج شبيهسازىهاى انجامشده ارائه مىشود. در ادامه

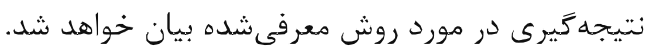

\section{Y - تعريف مسأله}

بهطور معمول كام ابتدايى در يكى الخوريتهم بهسازى كَفتار

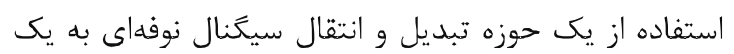
فضاى ويثزى جديد بهمنظور تحليل مناسبتر است. اين حوزه در روش بيشنههادى، فضاى تبديل موجى در نظر

${ }^{7}$ Supervised

${ }^{8}$ Semi-supervised

${ }^{9}$ Domain transfer

${ }^{10}$ Domain adaptation

${ }^{11}$ Incoherency

${ }^{12}$ Overcomplete

${ }^{13}$ Coherence
شنيدارى گَوش، بايد به باندهاى فركانسى مختلف تجزيه شود. در اين راستا، تبديل موجك از اين توانايى برخوردار بوده و مى تواند بهنحو مناسبى آناليز فركانسى انجامشده توسط زوش را با تجزيه سيخنال به زيرباندهاى مختلف به به

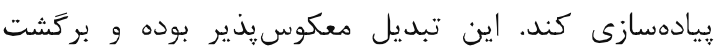

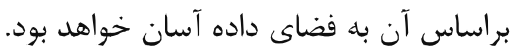

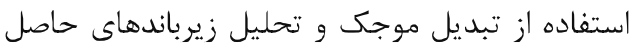

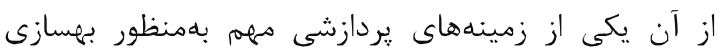

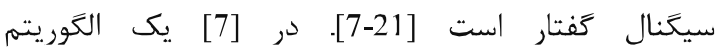
آستانه كذارى براى ضرايب موجك ارائه شده و مقايسه نتايج بهسازى آن با ساير روالهاى آستانهَذارى مورد بررسى قرى قرار

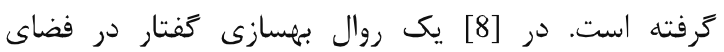
موجك با اعمال ضريب وزندهى در هر زيرباند ارائه شده

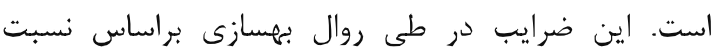
واريانس سيخنال تخمينى به واريانس سيخنال نوفهاى دولى

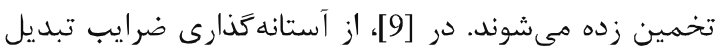
موجك در طراحى فيلتر وينر' در حوزه فركانس بلهمنظور

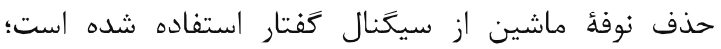
همجنين يك الخوريتم حذف نوفئ گفتار در [10] براساس

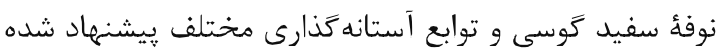

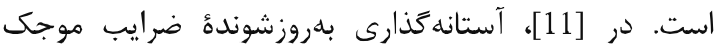
به كمك روال تجزيه حالت تجربى بـ و عمل در فضاى تبديل موجك بلمنظور حذف نوفه سفيد كوسى

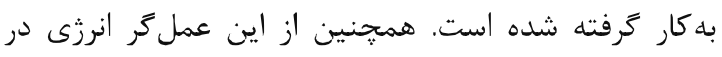

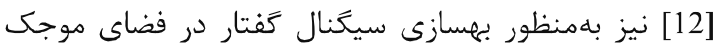

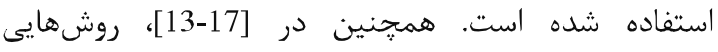
بهمنظور بهسازى كَفتار براساس ضرايب فضاى تبديل موجى

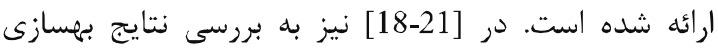

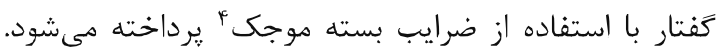
تجزيه باند تقريبه در اين تبديل نيز به موازات تجزيه باند

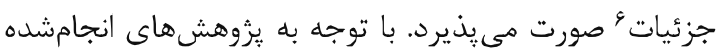

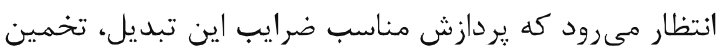

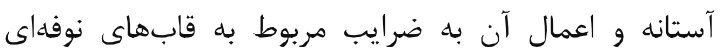

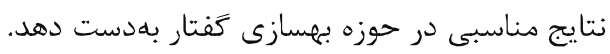
در روش ارائهشده در اين مقاله از مفاهيم بازنمايى بهني

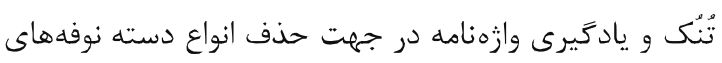
ايستا، نايستا و متناوب از سيخنال كَتار استفاده مىشود.

\footnotetext{
${ }^{1}$ Wiener filter

2 Empirical mode decomposition

${ }^{3}$ Teager energy operator

${ }^{4}$ Wavelet packet transform

${ }^{5}$ Approximation subband

${ }^{6}$ Detail subband
} 
مسأله كدكَارى تُنُك داده آهوزش بر روى وازهناهه هركب

$$
\text { بل بصورت زير بيان مىشود: }
$$

$C_{S}{ }^{*}, C_{N}{ }^{*}=\arg \min _{C_{S}, C_{N}}\|Y-D C\|_{2}$

$$
\begin{aligned}
& =\arg \min _{C_{S}, C_{N}} \| Y \\
& -\left[\begin{array}{ll}
D_{S} D_{N}
\end{array}\right]\left[\begin{array}{l}
C_{S} \\
C_{N}
\end{array}\right] \|_{2}
\end{aligned}
$$

ماتريسهاى

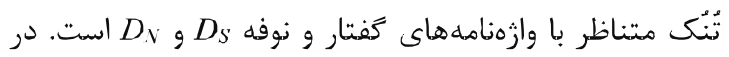

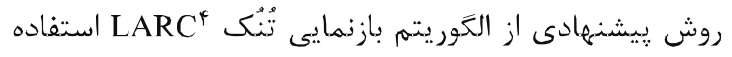

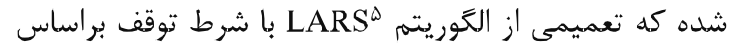

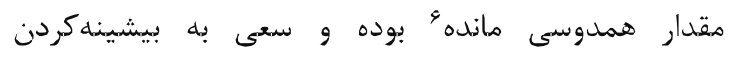

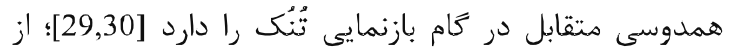
اينرو رابطه (ץ) مىتواند بهصورت زير بيان بارنيان شود:

$C_{S}{ }^{*}, C_{N}{ }^{*}=\operatorname{LARC}\left(\left[D_{S} D_{N}\right], K, C o h\right)$

مقدار بارامتر Coh

همدوسى ميان اتمدادة لازم براى يذيرش اتم بلعنوان ستونى

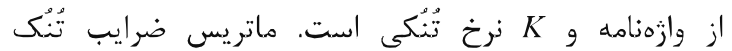

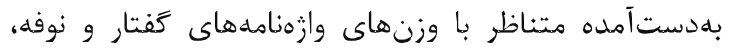
تخمينى از طيف كفتار $\hat{~}$ و طيف نوفه $\hat{S}=D_{S} C_{S}{ }^{*}, \widehat{N}=D_{N} C_{N}{ }^{*}$

درنظركرفتن معيار همدوسى مانده براى خاتمهدادن

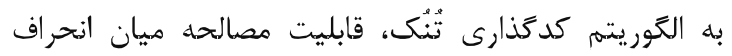

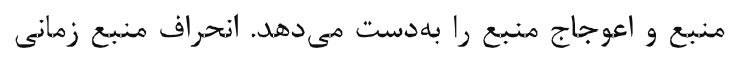

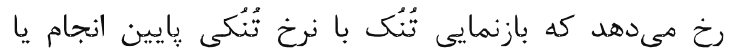

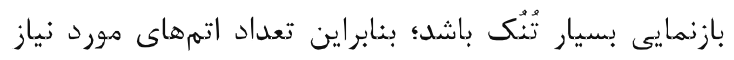

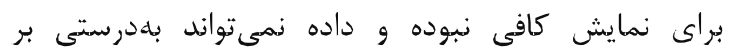
اتمهاى وازٔهنامه متناظر كد شود. اكر هر قاب تنهها با وازمنامه

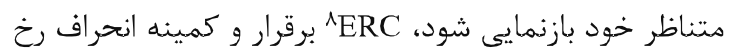

مى دهد [29]

$\left\|C_{S}{ }^{*}\right\|_{0}+\left\|C_{N}^{*}\right\|_{0}<\frac{1}{2}\left(1+\frac{1}{\mu\left(D_{S}, D_{N}\right)}\right)$

در اين رابطه، بر هقدار همدوسى ميان دو وازمناهه

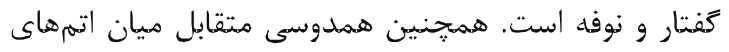

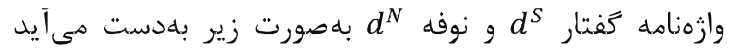

$\mu\left(D_{S}, D_{N}\right)=\max _{1 \leq i \leq L, 1 \leq j \leq L}\left|d_{i}^{S} \cdot d_{j}^{N}\right|$

\footnotetext{
${ }^{4}$ Least angle regression with coherence criterion

${ }^{5}$ Least-angle regression

${ }^{6}$ Residual coherence

${ }^{7}$ Coherence

${ }^{8}$ Exact recovery condition
}

گرفته شده است. سيخنال كَفتار نوفهاى در اين فضا بهصورت

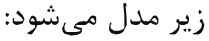

$Y(n)=S(n)+N(n)$

در اين رابطه S و N بهترتيب سيكنال كفتار و نوفه تجزيهشده در هر زيرباند n است. ماتريس داده يك سيك سيكنال

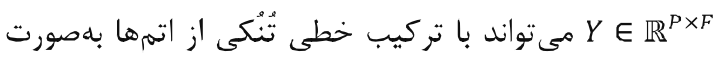

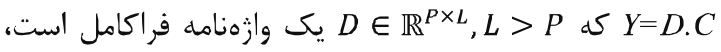

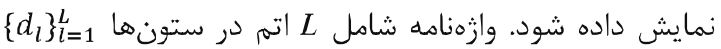
بانُرم واحد تُنُك' ' خ

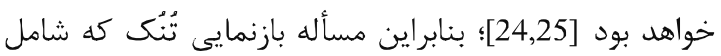
بخشهاى خطاى بازسازى و قيد تُنُكى است، بلهصورت زير قابل بيان است [24,25]:

$C^{*}=\arg \min \|Y-D C\|^{2},\|C\|_{0} \leq K$

تعداد ضرايب غيرصفر در ماتريس ضرايب تُنُك بdصورت

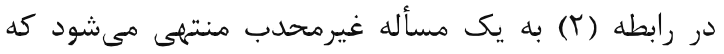
Nشوارَ است و ممكن است، موجب كرفتارشدن مسأله بهينهسازى در كمينههاى دحلى شود. آزادسازى " اين مسأله با جايكزينى نُرم

\section{r- ب- روش بيشنهيادى}

روندنماى روش پِيشنهادشده در اين هقاله كه شاهل دو

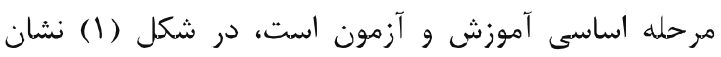

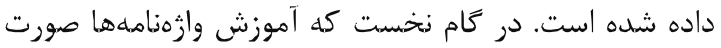

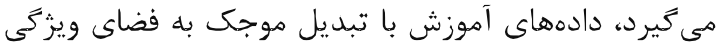

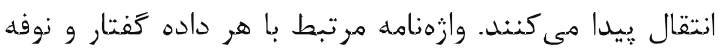
براساس روالى كه در ادامه معرفى مىشود، آموزش داده مىشود. توضيحات درخصوص هر يك از بلوكهاى اين روند در اداهه آورده شده است. نوصدات درح

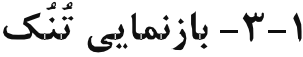

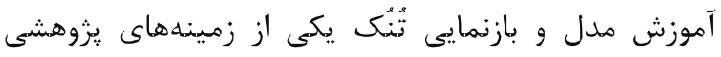
جديد در حوزههاى مختلف يردازش سيخنال است [27,28].

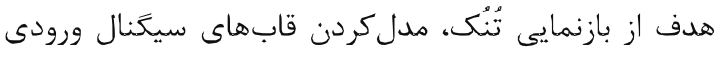
بهعنوان تركيب خطى از تعداد كمى از بردارهاى پِايه است.

\footnotetext{
${ }^{1} \mathrm{~K}$-sparse

${ }^{2}$ Non polynomial hard

${ }^{3}$ Relaxation
} 


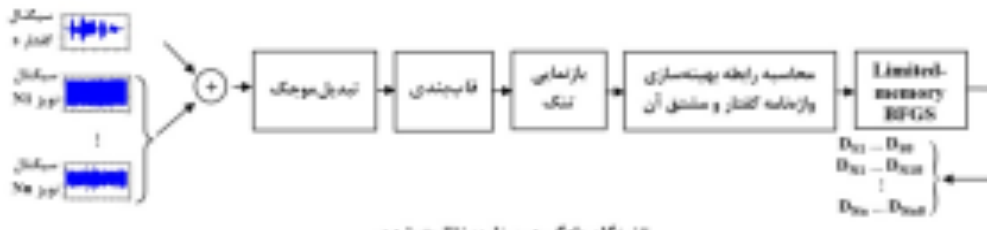

قب:

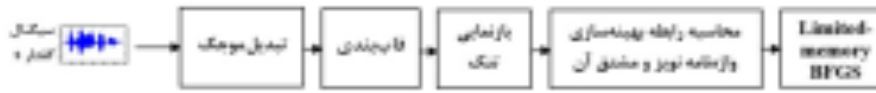

$\sin$

Bu

年

$1_{1}^{1}$
$\mathrm{D}_{\mathrm{a}}$
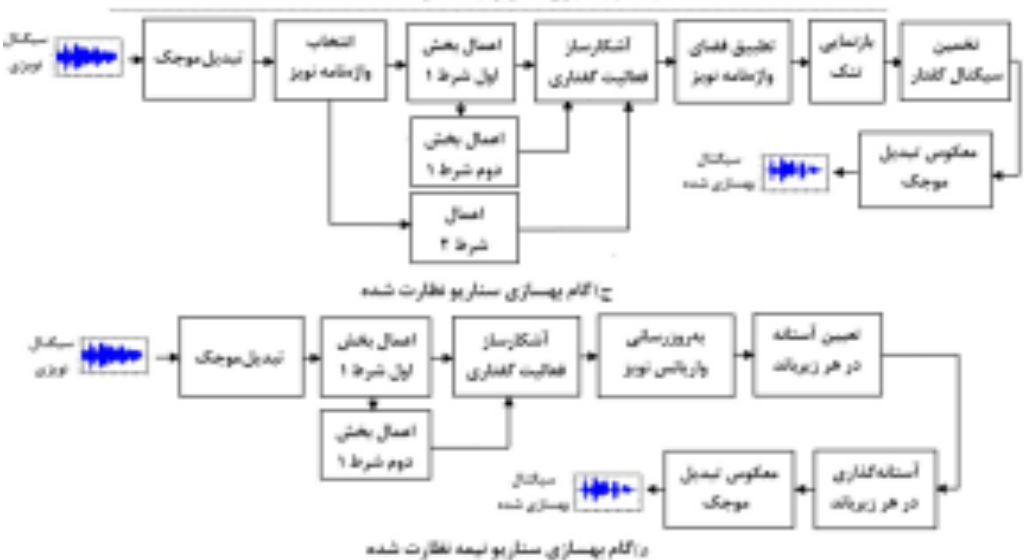

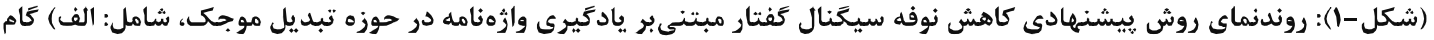

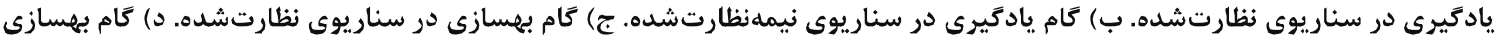
در سناريوى نيمهنظارتشده.

(Figure-1): The block diagram of the proposed speech enhancement method based on dictionary learning technique in wavelet transform domain included: a) Training step in the supervised scenario. b) Training step in the semi supervised scenario. c) Enhancement procedure in the supervised scenario. d) Enhancement procedure in the semi supervised scenario.

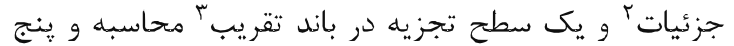
زيرباند متناظر براى هر قاب داده ورودى ايجاد مىشود. داده حاصل در هر يك از ينج باند، قاببندى و براى قابهرئ حاصل از هر زيرباند، يادَيرى وازمنامه بهصورت مجزا انجام

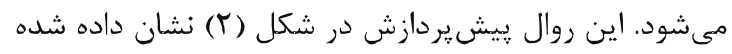
است. بلوك A و D در اين شكل بهترتيب مربوط به زيرباند

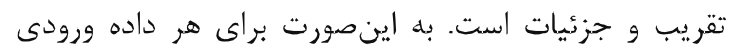

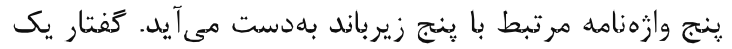

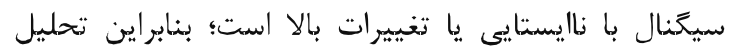

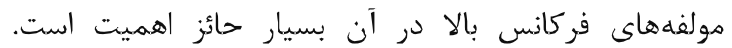

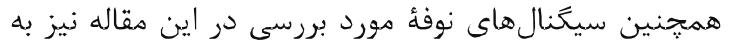

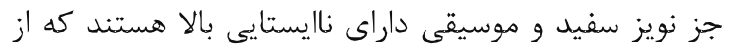

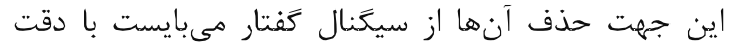
بيشتر انجام شود. بهمنظور بررسى دقيق مؤلفههاى فركانس بالا كه تحت تأثير شديد نوفه قرار مى كيرند، تحليل زيرباندهاى جزئيات از اهميت ويزهاى نسبت به باند تقريب

${ }^{2}$ Detail

${ }^{3}$ Approximation
از طرف ديكر، انتخاب هيارامتر تُنْكى با نرخ بالا يا

كدگذارى بسيار متراكم موجب اعوجاج منبع مىشود؛ يعنى

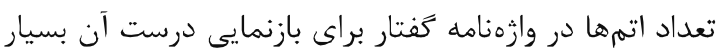
زياد خواهد بود و از برخى اتمهاى وازمنامه نوفه نيز در بازنمايى سيخنال كفتار استفاده مىشود؛ بنابراين انتخاب مقدار تُنُكى بايد بهدقت صورت يذيرد. در روش يِيشنهادى از

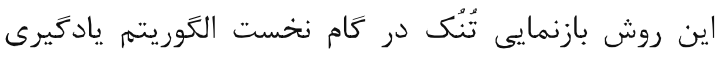

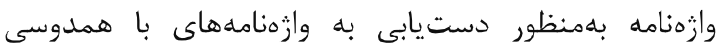

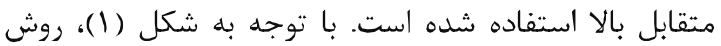

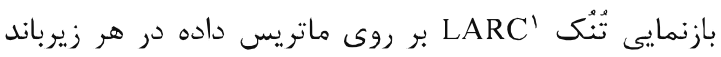
اعمال و ماتريس ضرايب تُنْك زيرباندها حاصل مىشوند [29].

\section{r-r} در كام آموزش، در ابتدا براى هر يك از سيخنال هاى گفتار و دادهاى نوفه، ضرايب موجك با سطح تجزيه سه در در باند

${ }^{1}$ Least angle regression with coherence criterion 
در اين رابطه

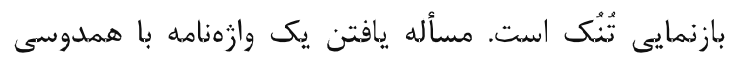

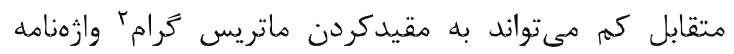
G $=D^{T} D$ مقدار مطلق عناصر غيرقطرى ماتريس گرام وقتى اتمها نرماليزه باشند، معرفى ميىشود [33].

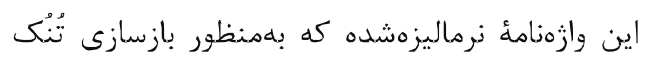

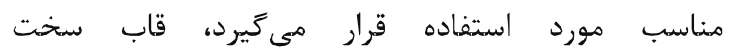

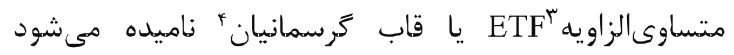
[34]؛ اما مسأله اساسى اين است كه اين ماتريس براى هر ابعاد دلخواه از وازثناهه وجود ندارد؛ بنابراين حل هسأله ائه بهصورت تقريبى انجام خواهد كرفت. يكى از نزديكترين

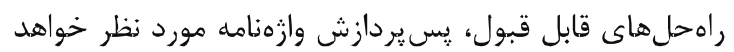
بود. هدف در روشهاى تقريبى مانند روش به كاركفتهشده در اين مقاله، كاهش مقدار خطاى تقريب دستيابى به ماتريس با كمينه همدوسى ميان اتمها خواهد

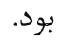
از آنجايى كه روش بازنمايى تُنُك OهP Oه انعطاف يذير است از نتايج حاصل از آن همراه با هر روش يادكيرى بانيى

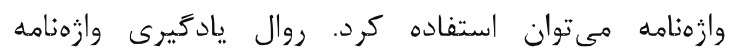

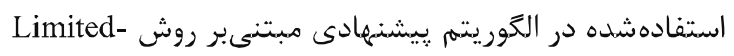
memory BFGS ${ }^{\varphi}$ حل مسائل بهينهسازى غيرخطى بدون قيد خواهد بود و

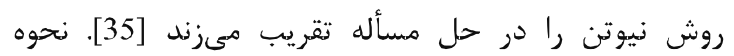

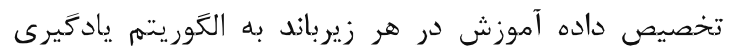

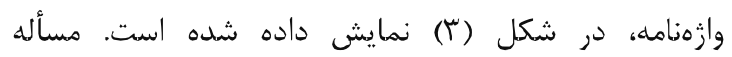

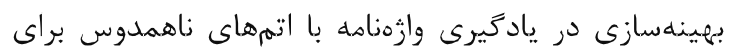

$$
\text { داده كَفتارى بهصورت زير خواهد بود: }
$$

$$
\begin{aligned}
F_{D_{S}}=\arg \min _{D_{S}} \| S & -D_{S} C_{S} \|_{F}^{2} \\
& +\gamma\left\|D_{S}^{\prime} D_{S}-I\right\|_{F}^{2}
\end{aligned}
$$

كه بخش زخست مربوط به كاهش خطاى تقريب داده

كفتار و بخش دوم مربوط به يافتن وازٔهناهه با ماتريس كرام

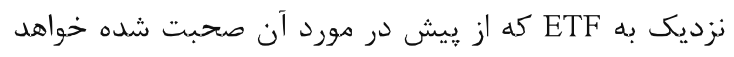

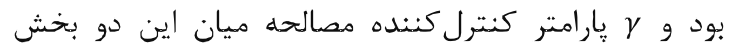
است. با درنظر گرفتن رابطه كلى

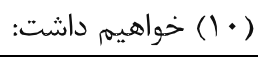

${ }^{2}$ Gram matrix

${ }^{3}$ Equiangular tight frame

${ }^{4}$ Grassmannian frame

${ }^{5}$ Orthogonal matching pursuit

${ }^{6}$ Broyden-Fletcher-Goldfarb-Shanno

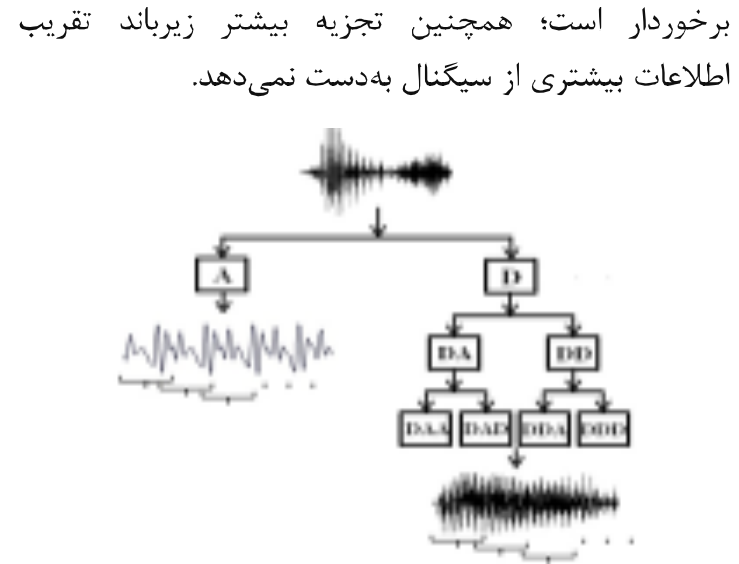

(شكل - Y): قاببندى داده هر زيرباند تبديل موجك براي تجزيه

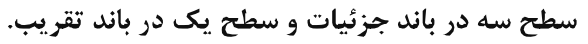

(Figure-2): Input data framing in the last subband of approximation and detail decomposition level.

يك روش يادگيرى مؤثر براى دست يابى به

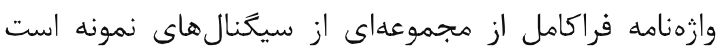

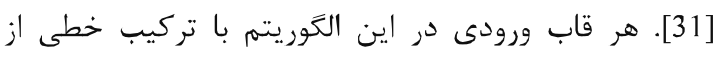
ضرايب K اتم در يك روش مبتنىبر تجزيه مقادير منفرد،

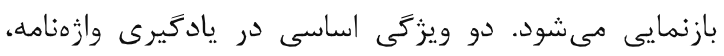
همدوسى متقابل و همدوسى بين اتمها است كه همدوسى بـى

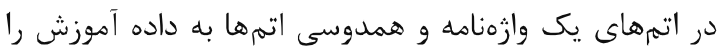

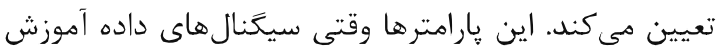
و نوفههاى مورد نظر ساختار يكسان دارند بايد بسيار مورد

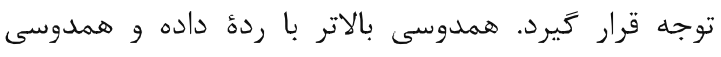
متقابل يايينتر ميان اتمها موجب مى هودود كه خطاى تقريب

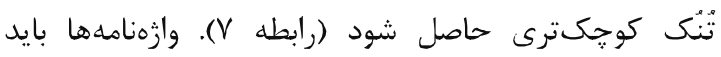
بيشترين ميزان همدوسى متقابل را داشته باشند تا مانع از

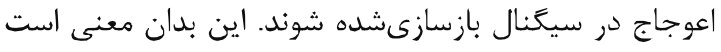

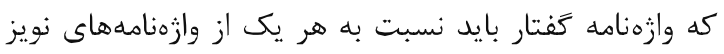
ناهمدوس باشد تا قابهاى مشاهدهشده از اين سيخنال بلهرستى بر روى وازهنامه متناظر، كدَذارى شود. اين معيار بهصورت زير محدود مىشود:

$\mu(D) \geq \sqrt{(L-P) / P(L-1)}$

در اين رابطه L التعداد اتمها و P بعد هر اتم است.

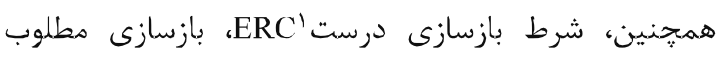

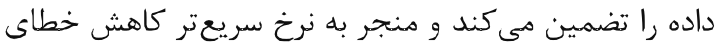

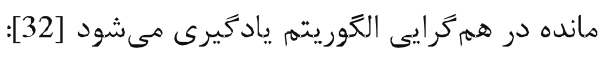

$\|C\|_{0}<\frac{1}{2}\left(1+\frac{1}{\mu(D)}\right)$

${ }^{1}$ Exact recovery condition 
حل با استفاده از روش Limited-memory BFGS بهصورت

$$
\begin{aligned}
\partial F_{D_{N}} / \partial D_{N}=2( & \left.D_{N} C_{N} C_{N}{ }^{\prime}-N C_{N}{ }^{\prime}\right) \\
& +4 \gamma_{1}\left(D_{N} D_{N}{ }^{\prime} D_{N}-D_{N}\right) \\
& +2 \gamma_{2}\left(D_{N}{ }^{\prime} D_{S} D_{S}{ }^{\prime}\right)
\end{aligned}
$$$$
\text { زير است: }
$$

تابع

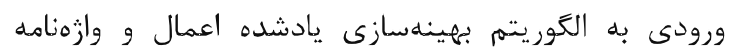
كفتار بههمراه وازهنامه براى هر نوع نوفه با نرخ ناهمدوسى

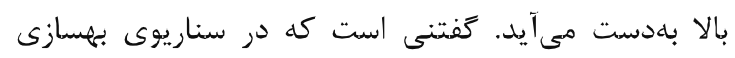
كفتار نظارتشده، هر دو هرحله ياد ئرى وازمناهه براى كفتار

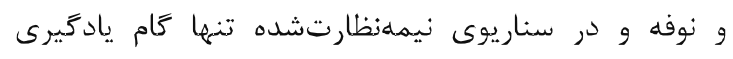
وازمنامه كفتار انجام مى شود.

\section{r-r - انتخاب وازهزامه نوفه}

سيخنال زوفهاى در كام بهرازى بيشنهادى در ابتدا به فضاى تبديل موجك انتقال مى يابد و سيس نوع نوفهاى كه كَفتار با

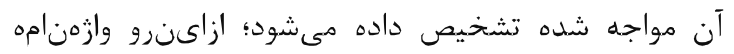

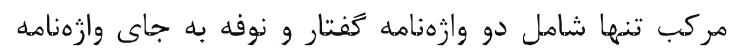
هركب متشكل از وازمنامه كفتار و تماهى وازمنامههاى نوفه خواهد بود. اين مسأله موجب مىشود كه من نتايج در بازنمايى تُنُك كام بهسازى با سرعت بيشترى رخ دهد دهد و و با مشكلات

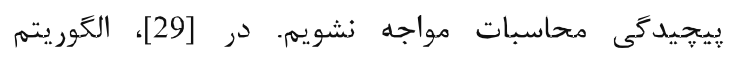
بهسازى كفتار ديخرى با استفاده از يادكيرى وازثنامه هطرح

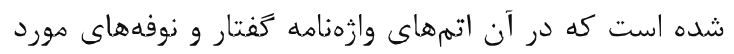
بررسى بهصورت برون خط آموزش هىبينند. داده نوفئ مورد

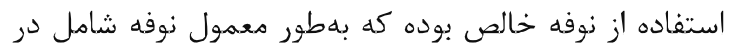

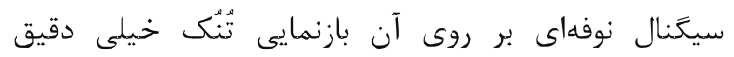

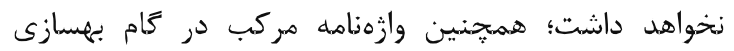

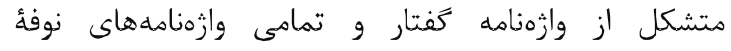
آهوزشديده است. اين هسأله ممكن است، عملكرد الكوريتهم

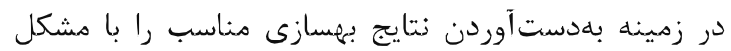
مواجه كند و منجر به كدگذارى خيلى متراكم سيخنال كفتّار

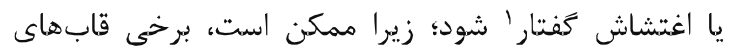

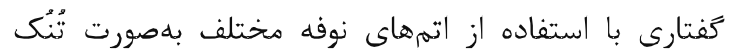

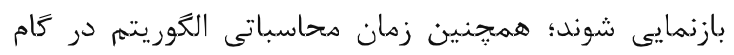
بهسازى بهعلت ابعاد بالاى وازمنامه مركب بسيار بالا خواهد بود. مسأله ديكر اين است كه ساختار مؤلفههاى برخى قابها در سيخنالهاى نوفه مختلف بهصورت ذاتى مشابه هستند. ازاينرو در وازمنامه هركب حاصل، اتمهاى هشابه وجود

${ }^{1}$ Speech confusion

$$
\begin{aligned}
& F_{D_{S}}=\operatorname{tr}\left\{C_{S}{ }^{\prime} D_{S}{ }^{\prime} D_{S} C_{s}\right\}-2 \operatorname{tr}\left\{S^{\prime} D_{S} C_{S}\right\} \\
& \\
&+\operatorname{tr}\left\{S^{\prime} S\right\} \\
&+\gamma\left(\operatorname{tr}\left\{D_{S}{ }^{\prime} D_{S} D_{S}{ }^{\prime} D_{S}\right\}\right. \\
&\left.-2 \operatorname{tr}\left\{D_{S}{ }^{\prime} D_{S}\right\}+\operatorname{tr}\{I\}\right)
\end{aligned}
$$

كه سه بخش نخست مربوط به خطاى تقريب و مابقى بخشها مربوط به ماتريس كرام ETFاست. بهمنظور حل اين مسأله به كمك روش Limited-memory BFGS، مى مبايست

$$
\begin{gathered}
\partial F_{D_{S}} / \partial D_{S}=2\left(D_{S} C_{S} C_{S}{ }^{\prime}-S C_{S}{ }^{\prime}\right) \\
+4 \gamma\left(D_{S} D_{S}{ }^{\prime} D_{S}-D_{S}\right)
\end{gathered}
$$

مسأله بهينهسازى يادگيرى وازمنامه نوفه با اتمهاى ناهمدوس نسبت به اتمهاى يادگيرىشده براى داده گفتتارى در مرحله قبل، بهصورت زير بيان مىشود:

$$
\begin{aligned}
F_{D_{N}}=\arg \min _{D_{N}} \| & N-D_{N} C_{N} \|_{F}^{2} \\
& +\gamma_{1}\left\|D_{N}{ }^{\prime} D_{N}-I\right\|_{F}^{2} \\
& +\gamma_{2}\left\|D_{N}{ }^{\prime} D_{S}\right\|_{F}^{2}
\end{aligned}
$$

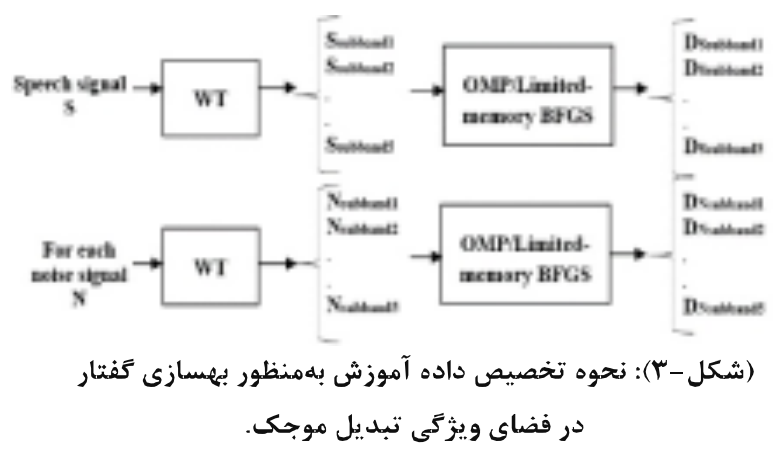

(Figure-3): Training process of speech and noise signals in different subbands of wavelet transform.

بخش نخست در اين رابطه مربوط به كاهش خطاى

تقريب داده نوفه، بخش دوم مربوط به يافتت وازمنامه نوفه با ماتريس كرام نزديك به ETF و بخش سوم مربوط با يافتن اتمهاى وازمناهه نوفئه مستقل از اتمهاى وازمهزاهه كفتتار است.

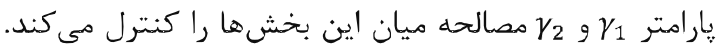
با سادهردن اين رابطه خواهيم داشت:

$$
\begin{aligned}
F_{D_{N}}= & \operatorname{tr}\left\{C_{N}{ }^{\prime} D_{N}{ }^{\prime} D_{N} C_{N}\right\}-2 \operatorname{tr}\left\{N^{\prime} D_{N} C_{N}\right\} \\
& +\operatorname{tr}\left\{N^{\prime} N\right\} \\
& +\gamma_{1}\left(\operatorname{tr}\left\{D_{N}{ }^{\prime} D_{N} D_{N}{ }^{\prime} D_{N}\right\}\right. \\
& \left.-2 \operatorname{tr}\left\{D_{N}{ }^{\prime} D_{N}\right\}\right) \\
+\operatorname{tr}\{I\}+ & \gamma_{2}\left(\operatorname{tr}\left\{D_{S}{ }^{\prime} D_{N} D_{N}{ }^{\prime} D_{S}\right\}\right)
\end{aligned}
$$

در اين رابطه سه بخش نخست مربوط به خطاى تقريب، سه بخش دوم مربوط به بخش ماتريس زرام با ناهمدوسى بالا و بخش آخر مربوط به ناهمدوسى متقابل

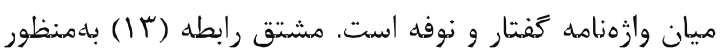


بالا باشد، به معناى اطمينان به تصميم گرفتهشده مبنى بر

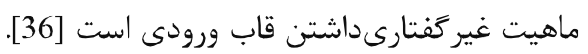
اين شرط مخصوص سناريوى نيمهنظارتشده است و

اگر سناريو نظارتشده باشد شرط ديكرى نيز براى اطمينان

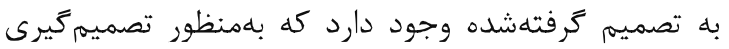
مناسب در كنار شرط نخست قرار مى توجه به دراختياربودن وازمنامه نوفه علاوهبر وازهنامه كفتار درنظر زرفته مىشود. در شرط دوم انرزى ماتريس ضرايب

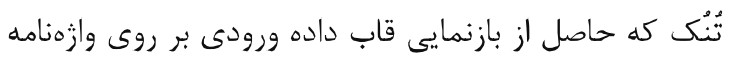
مركب است، بررسى مىشود. وازمنامه مركب همانطور كه از ييش بيان شده از كنار هم قرارگرفتن وازمنامه كفتار و و وازمنامه نوفه انتخابشده بهدست مى آيد. از مقايسه انرزى سيان متناظر با هر وازٔنامه مىتوان تصميم مناسبى درخصوص ماهيت قاب ورودى اتخاذ كرد. اگر قاب ورودى كَفتارى باشد، انرثى ضرايب تُنُك آن بر روى وازْهنامه كفتار بسيار بالاتر از

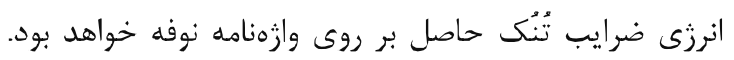
اگر اين شرط در هر جهار زيرباند تقريب برقرار باشد، برجسب كفتارى از شرط دوم به قاب ورودى اختصاص

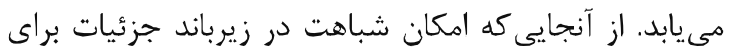
داده كفتار و نوفه زياد است، تأثير مقايسه انرزى ضرايب ايب اين

مجموعه كمتر خواهد بود [36].

بررسى شرط نخست: تعيين ميزان شباهت ميان

قاب داده و قاب داده بازسازى شده:

$C=O M P\left(Y, D_{S}\right) \rightarrow \hat{Y}=D_{S} . C \rightarrow\langle Y, \hat{Y}\rangle$ $=Y \cdot \hat{Y} /\left(\|Y\|_{2} \cdot\|\hat{Y}\|_{2}\right)$

ا - اكر ع مشاهدهده است، بازنمايى بر روى قابهاى اوليه نوفهاى

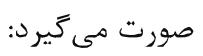

$C_{0}=\operatorname{LARC}\left(Y, D_{N 0}\right) \rightarrow 1 / L \sum_{l=1}^{L} \mathrm{C}_{0}^{2}$

اءر انرزى ضرايب تُنُك در اين بازنمايى كم باشد به

معناى دارابودن برجسب گفتارى براى قاب ورودى است. Lا،

در اين رابطه طول قاب مورد بررسى خواهد بود. Y- به همين صورت اگر ع نوفهاىبودن قاب مشاهدهشده است، بازنمايى بر روى روى قابهاى اوليه نوفهاى صورت مى حيرد؛ اكر انرزى ضرايب تُنُك در اين بازنمايى زياد باشد، به معناى اطلاق برجسب

$$
\text { غير گفتارى به قاب ورودى است. }
$$

خواهند داشت و مؤلفؤ نوفه سيخنال مشاهدهاى بهدرستى

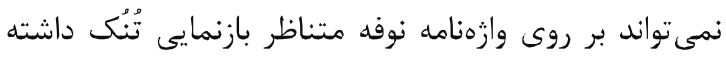
باشد. بهمنظور انتخاب نوع نوفه، قابهاى اوليه سكوت تَفتار

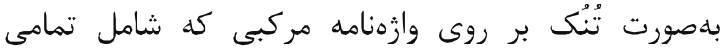

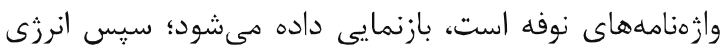

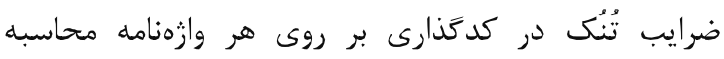
مىشود. نوع نوفة مشاهدهشده با توجه به وازٔنامه نوفه با بيشترين انرزى ضرايب بازنمايى حاصل مىشود؛ زيرا هر رده

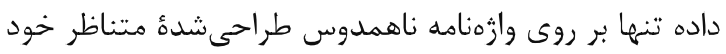
بازنمايى خواهد داشت. ازاينرو، وازهنامه مركب حاصل از وازّهنامه گفتار و تنها وازهنامه نوفه انتخابى، زمان محاسباتى براى اجراى روال بهسازى را بهطور جشمَّى كاهش مى دهد.

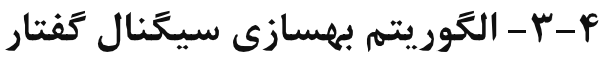

در نخستين مرحله از كام بهسازى، برجسب قابهاى

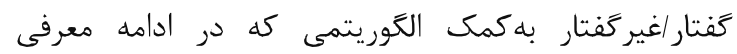
مىشود، تعيين مىشود. در اين روال كه براى هر زيرباند و

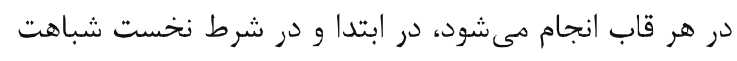

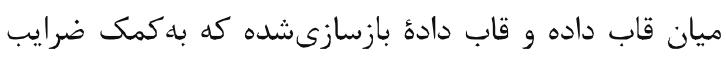

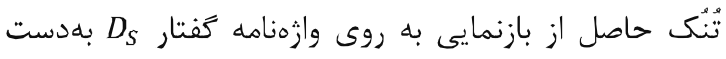
مى آيد، بررسى مىشود. اخر شباهت ميان اين دو قاب زياد

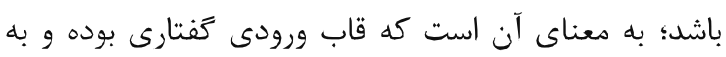
همين دليل بر روى وازّنامه كَفتار بازنمايى مناسب داشب واشته

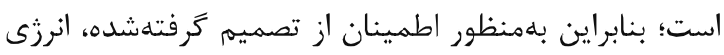

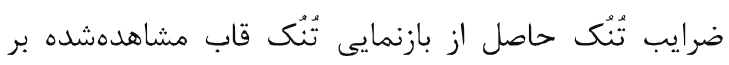
روى قابهاى ابتدايى و انتهايى سيخنال كفتار كه ساختار

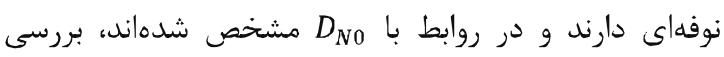
مىشود. اكر انرزى ضرايب تُنُك كم باشد، به معناى اين است

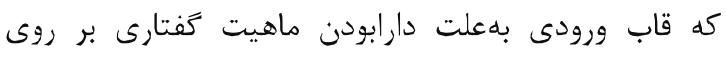
اتمهاى با ماهيت نوفهاى، بازنمايى مناسب نداشته و تصميم كرفتهشده در مورد كفتارىبودن قاب مورد بررسى درست ماهي

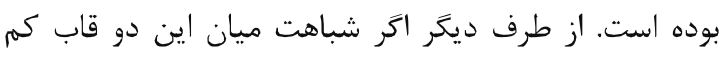
باشد كه به معناى خطاى بازنمايى زياد قاب ورودى بر روى إن إن

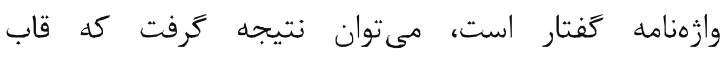
غير كفتارى است. بنابراين بهمنظور اطمينان بيشتر به تصميمم گرفتهشده، قاب ورودى بر روى قابهاى داده ابتدايى و

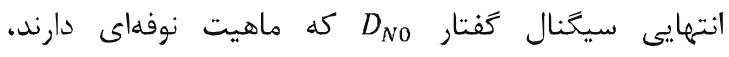
بازنمايى مى شوند و اخر انرثى ضرايب تُنْك در اين بازنمايى 
وازهنامه مركب حاصل از وازهنامه كفتار و اين وازهنامه تطبيقيافته انجام مى كيرد [36]:

$Y=\left[D_{S} \widehat{D}_{N}\right]\left[\begin{array}{l}C_{S} \\ \hat{C}_{N}\end{array}\right] \rightarrow \hat{S}=D_{S} \cdot C_{S}$

در سناريوى نيمهنظارتشده كه وازهنامه نوفه در

دسترس نيست، بهكمى روابط بلروزكردن تخمين نوفه در

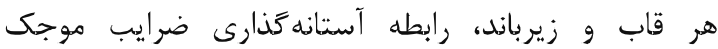
متناسب با سطح نوفهاى كه قاب درگير آن است، تغيير

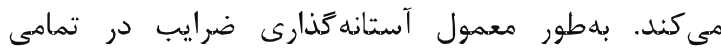

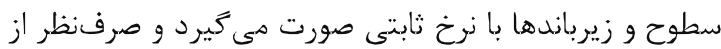

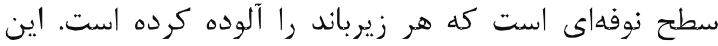
مسأله موجب عدم دستيابى به نتايج مطلوب در فرآيند بهرازى مىشود؛ بنابراين در روش پِيشنهادى با توجه به

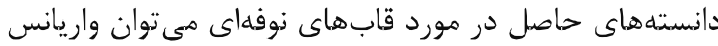
نوفه را در هر قاب بهروز كرده و حذف ضرايب با توجه به آن در هر زيرباند صورت گيرد. همانطوركه بيان شد روندنماى كلى روش بيشنهادى در حوزه تبديل موجك بهتفكيكى دو سناريوى نظارتشده و نيمه نظارتشده مورد بحث درو در شكل (1) (1) (1) نمايش داده شده است.

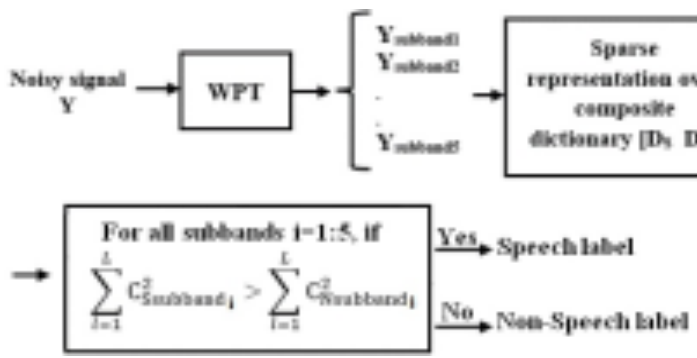

(شكل -F): نحوه عملكرد آشكار ساز فعاليت كفتارى بيشنيهادشده در فضاى تبديل موجك در هر زيرباند با درنظركرفتن شرط دوم. (Figure-4): The procedure of label detection in the proposed energy-based VAD algorithm in different subbands of wavelet decomposition.

زاسئ

همجنين تابع آستانهَذار بهصورت زير خواهد بود:

$\hat{Y}=\left\{\begin{array}{cc}Y-\frac{1}{2} \frac{T_{j}^{2}}{Y}, & |Y| \geq T_{j} \\ \frac{1}{2} \operatorname{sign}(Y) \cdot \frac{|Y|^{2}}{T_{j}}, & |Y|<T_{j}\end{array}\right.$

در اين رابطه شيب حذف ضرايب در تابع آستانه گذار متناسب با سطح نويز تغيير هى كند. هر جققدر هقدار ياراهتر آستانه T T بيشتر باشد به اين معنا است كه نوفه بيشترى

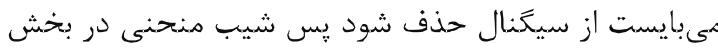
足 $|Y|<T_{j}$

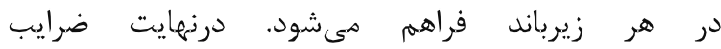
آستانهَذارىشده حاصل با تبديل معكوس موجك به به فضاى داده بر گشت داده مىشوند.
بررسى شرط دوم: در ابتدا بازنمايى تُنُك بر روى وازهنامه مركب انجام و سيس انرزى ضرايب متناظر با هر

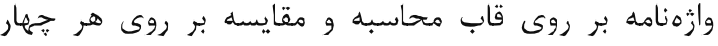

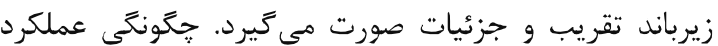
اين شرط در آشكارساز فعاليت كَفتارى هيشنهادى براى هر زيرباند تبديل موجك در شكل (أl) نشان داده شده است؛ درنهايت مىتوان با توجه به نتايج حاصل از شرط نخست و وند

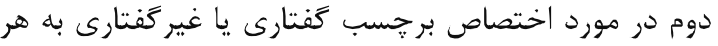

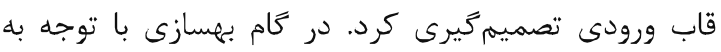
نتايج بهدستآمده در مرحله قبل و تشخيص قابهاى كفتار | غير گفتار، با توجه به سناريوى مورد بررسى دو راهكار

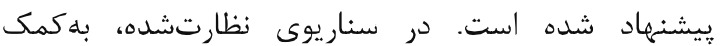
قابهاى نوفهاى بلهدستآمده از نتايج مرحله قبل و تكنيك تطبيق فضا، اتمهاى وازمناهه نوفه از ييش يادكيرىشده متناسب با شرايط نوفه محيط آزمون و بهمنظور انطباق بيشتر با آن بهروز مىشوند؛ كه اين وازهنامه تطبيقيافته با

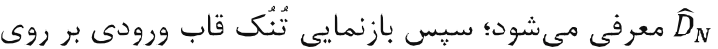

بايد توجه داشت كه هر يك از اين مراحل براى هر زيرباند از ينج زيرباند مورد بررسى انجام مى گيرد. رابطه بهروزرسانى سطح نوفه در هر قاب بهصورت زير خواهد بود:

$\widehat{N}_{j, n}=\alpha \widehat{N}_{j, n-1}+(1-\alpha) Y_{j, n}^{2}$

ز شماره زيرباند و n شماره قاب است. انحراف معيار

نويز در هر زيرباند بهصورت زير در نظر گرفته ميىشود [35]: $\hat{\sigma}_{j}=\operatorname{median}\left(\left|\widehat{N}_{j}\right|\right) / 0.6745$

عبارت median بيانگر انحراف مطلق ميانه' است.

محاسبه دقدار آستانه در هر زيرباند بهصورت زير است [37]: $T_{j}=\hat{\sigma}_{j} \sqrt{2 \ln \left(L_{j}\right)}$

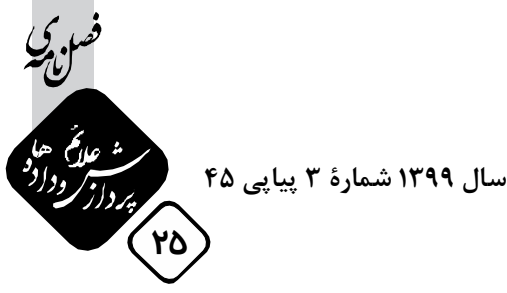

${ }^{1}$ Median absolute deviation 
(جدول-1): مقادير همدوسى متقابل ميان اتمها و S.NR تقريب سيكنال داده براى وازٔهنامه كَفتار و نوفه بر حسب dB در روش هاى مختلف. (Table -1): The atom coherence and SNR values in signal reconstruction for speech and noise dictionaries using different methods.

\begin{tabular}{|c|c|c|c|c|c|c|c|c|c|c|}
\hline بيانو & رستوران & قطار & خيابان & ماشين & سفيد & كارخانه & همرماه & كفتار & & \\
\hline .194 & $\cdot 119$ & $\cdot \mid 1 \Lambda$ & $\cdot / 9$. & .119 & $.19 r$ & .191 & $\cdot 119$ & $\cdot \mid \wedge V$ & همدوسى & \multirow{2}{*}{ K-SVD /OMP } \\
\hline $11 / 1$ & $1 \cdot 11$ & $1 \cdot / V$ & IT & $|Y /|$ & $11 / r$ & $1 \cdot 11$ & $1 \cdot 19$ & $I T / F$ & SNR & \\
\hline.$/ 98$ & .191 & .119 &.$/ 95$ & $.19 F$ &.$/ 9 \Delta$ &.$/ 9$. & . $/ A T$ & $\cdot / V 8$ & همدوسى & \multirow{2}{*}{ K-SVD /LARC } \\
\hline $11 / \pi$ & $1 \cdot / \mathrm{V}$ & $1 \cdot / 4$ & $11 / 1$ & $11 / 8$ & $11 / 1$ & $1 \cdot 11$ & $1 \cdot 19$ & $I T / F$ & SNR & \\
\hline .10 &.$/ 4 T$ &.$/ 49$ &.$/ F \Delta$ &.$/ F F$ & .148 &.$|F|$ &.$/ 49$ &.$/ 4 V$ & همدوسى & \multirow{2}{*}{ روش پِيشنههادى (رابطه 9) } \\
\hline $11 / 0$ & $11 / r$ & 11 & $I T / T$ & $\mid r / r$ & $11 / 8$ & $11 / r$ & $11 / r$ & $\mid r / \Delta$ & SNR & \\
\hline
\end{tabular}

(جدول - (Y): مقادير همدوسى متقابل ميان اتمهاى وازٔهزامه كَفتار و هر يك از وازٔهنامههاى نوفه در روش هاى مختلف. (Table -2): The mutual coherence between speech and each of noise dictionary atoms using different methods.

\begin{tabular}{|c|c|c|c|c|c|c|c|c|}
\hline 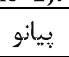 & ر رستوران & 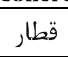 & خيابان & ماشين & سفيد & كارخانه & هميمله & \\
\hline$\cdot / V V$ & .191 & .19 & $\cdot / 19$ & $\cdot 119$ & $\cdot / V A$ & $\cdot / \wedge \Delta$ &.$/ 9 r$ & K-SVD/OMP \\
\hline$\cdot / V T$ & .194 & .19 &.$/ 91$ & $\cdot / / \Lambda$ & $\cdot / \mathrm{r}$ & $\cdot / \mathrm{AV}$ &.$/ 91$ & K-SVD/LARC \\
\hline$\cdot \mid \Delta q$ & $\cdot / 84$ & .109 & $+|8|$ & . & $\cdot / \Delta V$ & $.19+$ & .181 & روش بيششنهادى (رابطه rI) \\
\hline
\end{tabular}

سطح تجزيه باند جزئيات برابر سه درنظر كرفته شده است.

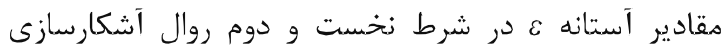

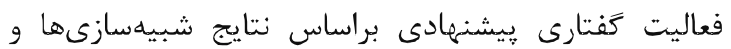
بهصورت تجربى تنظيهم شدهاند. اين مقدار براى تماهى

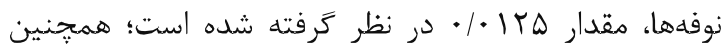
يارامتر ه براساس نتايج تجربى و براى تماهى نوفهها به مقدار

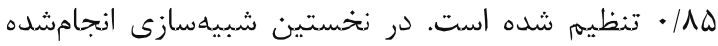

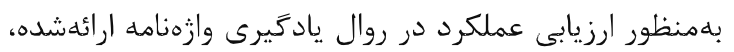
دو يارامتر همدوسى هتقابل اتمها و همدوسى اتمهاى

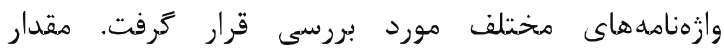
همدوسى متقابل اتمها در وازّنامه كفتار و وازمنامههاى نوفه بهدستآمده از رابطه (V) براى روشهاى هاى يادخيرى وازهنامه

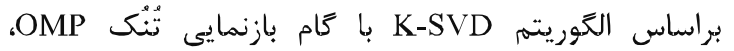

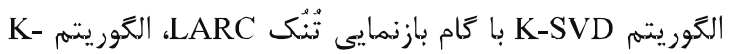
و با كام بازنمايى تُنُك SVD Limited memory- روش استفادهشه در اين مقاله براساس BFGS در جدول (1) نشان داده شده است. در اين جدول، مقدار SNR

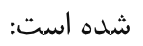

$S N R(Y, D C)=20 \log _{10}\left(\|Y\|_{F} /\|Y-D C\|_{F}\right)$

در اين رابطه Y، سيگنال تقريب زدهشده در بازنمايى تُنْى

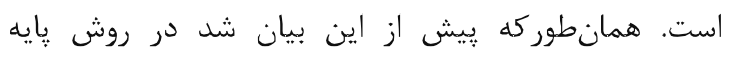
يادكيرى وازمنامه هبتنىبر K-SVD/OMP هيجَّونه روش كاهش همدوسى متقابل اتمرها بهكارگرفته نشده است. به
F - جزئيات شبيهسازى شبيهسازىهاى انجامشده بر روى هجموعهدادًان جاهع

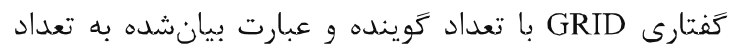
زياد انجام كرفته كه مناسب براى شبيهسازىهاى اين مقاله

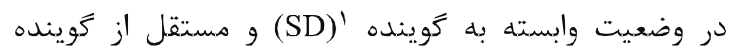

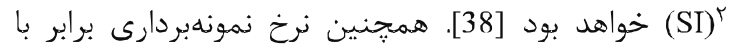
^kHz دو وضعيت مستقل از كوينده (كويندههاى متفاوت در مرحله

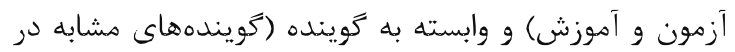

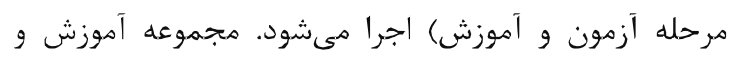

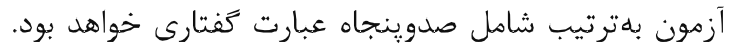
از اين هيان هشت گَوينده زن و هشت كوينده مرد در كام

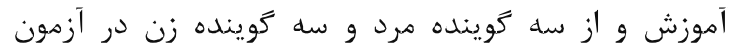

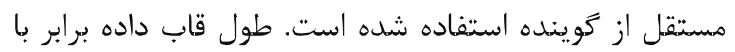
د.ms در روال يادكيرى براى همل هنابع داده شامل كفتار و ونمان نوفههاى مختلف يكسان است. نرخ افزونكى وازمنامه كفتار

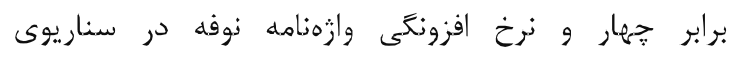
نظارتشده نيز برابر همين مقدار در نظر زرفته شده است. شبيهسازى بر روى محدوده گستردهاى از سيخنالهاى نوفه

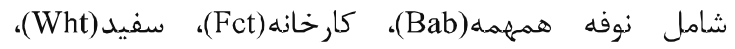
ماشين(Car)، خيابان(Str)، قطار (Trn)، رستوران(Rst) و نوفه موسيقى ييانو(Pno) از وبسايت جامعه ييانو صورت گرفته است [39-39]؛ همجنين با توجه به بررسىهاى انجامشده،

${ }^{1}$ Speaker dependent

${ }^{2}$ Speaker independent 
[41] و روش پايه آستانه كذارى دوجك BWT" با تابع آستانه نرم معرفىشده در [3] است؛ همجنين عملكرد الكَوريتم با روش ارائهشه در [43]، روش هبتنىبر يادكيرى وازمناهه

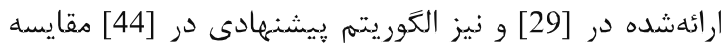

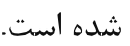

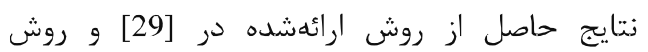

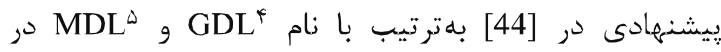

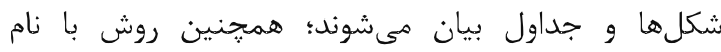
AWPT

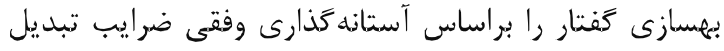

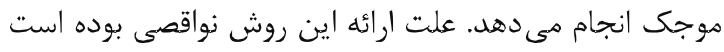

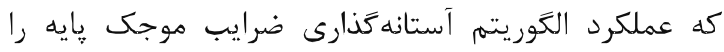

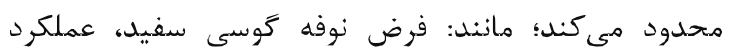

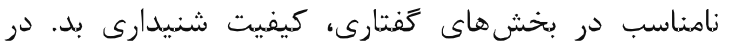

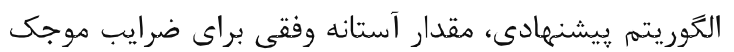

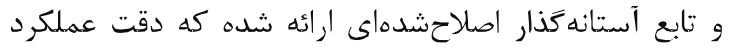

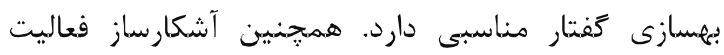

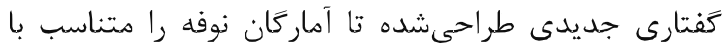

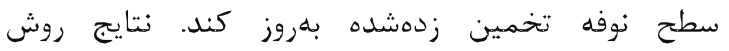

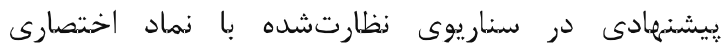
((Proposed_Sup)) (Proposed_Semi))

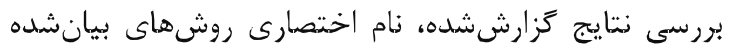

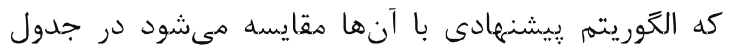

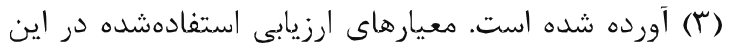
مقاله (جدول - r): نام اختصارى روش هاى مقايسهشده با الكَوريتم

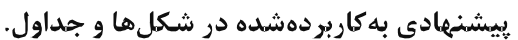

(Table -3): The abbreviation name used for each comparison

\begin{tabular}{|c|c|c|}
\hline مرجع & نام روش & زام اختصارى \\
\hline$[40]$ & تفاضل طيفى هندسى & GSS \\
\hline [2] & تفاضل طيفى جندباند & MBSS \\
\hline$[42]$ & يادكيرى وازٔناهه اصلاح شده & MDL \\
\hline$[27]$ & يادَّيرى وازمناهه مولد & GDL \\
\hline [3] & روش پايه آستانه كذارى موجك & BWT \\
\hline$[41]$ & بسته هوجك تطبيقى & AWPT \\
\hline- & روش يبشنههادى نظارتشده & Proposed_Sup \\
\hline- & روش يِيشنهادى نيمه نظارتى & Proposed_Semi \\
\hline
\end{tabular}

${ }^{2}$ Geometric spectral subtraction

${ }^{3}$ Basic wavelet thresholding algorithm(BWT)

${ }^{4}$ Gencrative dictionary learning(GDL)

${ }^{5}$ Modified dictionary learning(MDL)

${ }^{6}$ Adaptive wavelet packet thresholding

${ }^{7}$ Frequency-weighted segmental signal to noise ratio

${ }^{8}$ Perceptual evaluation of speech quality
همين دلايل مقادير همدوسى كزارششده براى اين روش

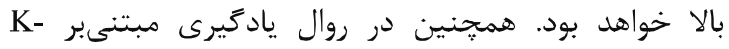
SVDD/LARC

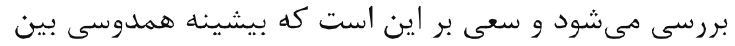
اتمها و رده داده مورد نظر برقرار شود آدود [29]. بنابراين مقدار

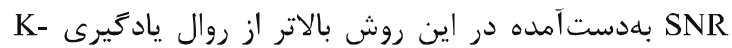
K- خواهد بود؛ همجنين، در روال يادكيرى SVD/OMP

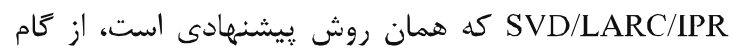
يسيردازش IPR بهمنظور كاهش همدوسى متقابل اتمهاى

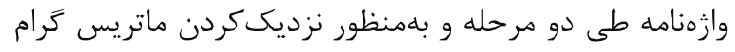
وازهنامه به ساختار ETF استفاده شده، [34] به همين دليل مقادير همدوسى متقابل اتمها در اين روش يادگيرى

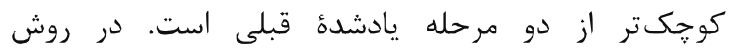
بدكاركرفتهشده در اين مقاله، بخشى از تابع بهينهسازى مورد

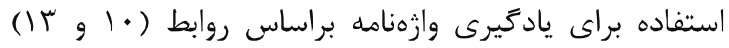
بهنظور يافتن ساختار ETF براى وازهنامه درنظر كرفته شده است و بهينهسازى اتمها بر اين مبنا و همراه با كاهش خطاى تقريب داده صورت مىيذيرد. همانطوركه ديده مىشود، روال بهينهسازى مبتنىبر روش - Limited memory

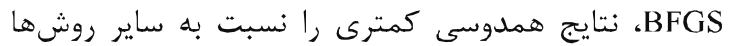
كزارش مى دهد. در ادامه همدوسى متقابل ميان اتمهاي

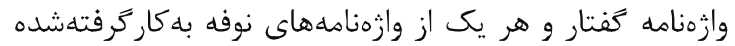
در روال بهسازى مورد بررسى قرار كرفت. اين مقادير همدوسى در جدول (r) تزارش شده است. در سه رون روش

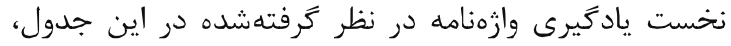
مقادير همدوسى متقابل اتمهاى كفتارى و هر يكى از نوفهها مقادير بالايى دارد؛ زيرا در اين روشها روالى رالى براى كائ كاهش

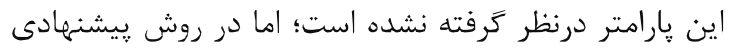

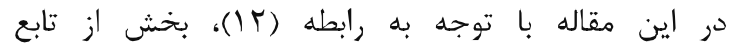
بهينهسازى مبتنىبر كاهش مقدار همدوسى متقابل اتمهاى واثهنامه نوفه و كَفتار درنظر كرفته شده است. مقدار

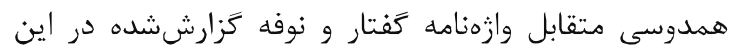

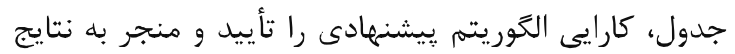

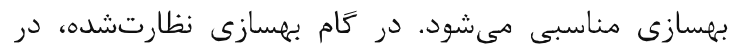

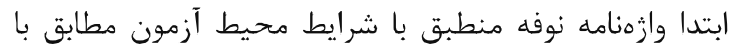

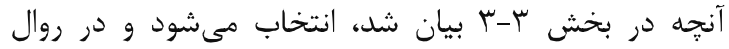

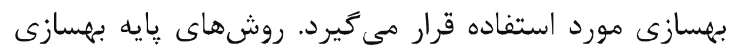

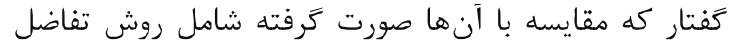

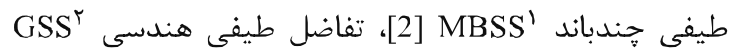

\footnotetext{
${ }^{1}$ Multi band spectral subtraction
} 
شكلهاى (ه و \&)، اين نتايج در جداول (f و ه) كزارش شده است. نتايج حاصل از اين معيارها در حالت وابسته به كَّينده

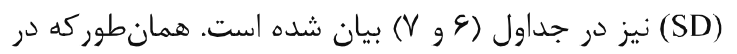
شكلها و جداول مشاهده مىشود، روش رِيشنهادى نتايج

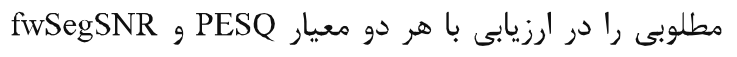

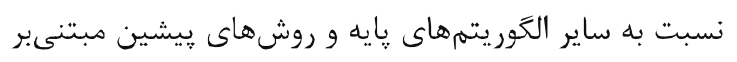

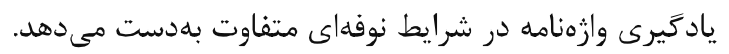

نتايج بهسازى حاصل از روشهاى يادشده براى اين

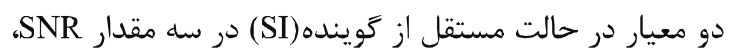
كارخانه (BdB

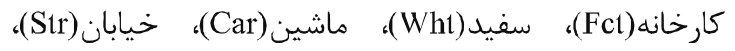

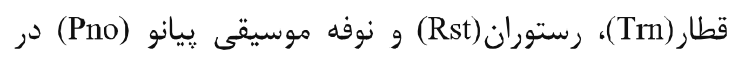
شكلهاى (له و \&) نشان داده شده است. اين نتايج در مقادير

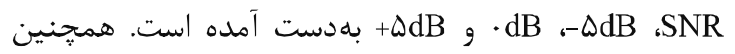
بهمنظور نمايش بهتر تفاوت ميان دسته روشهاى مختلف در أرد

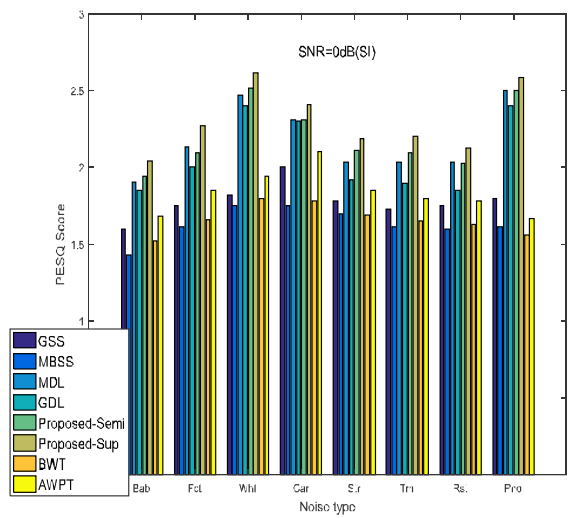

(b)

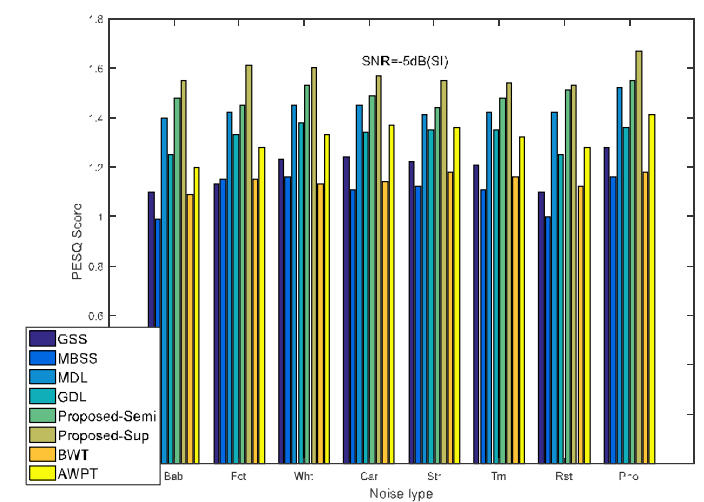

(a)

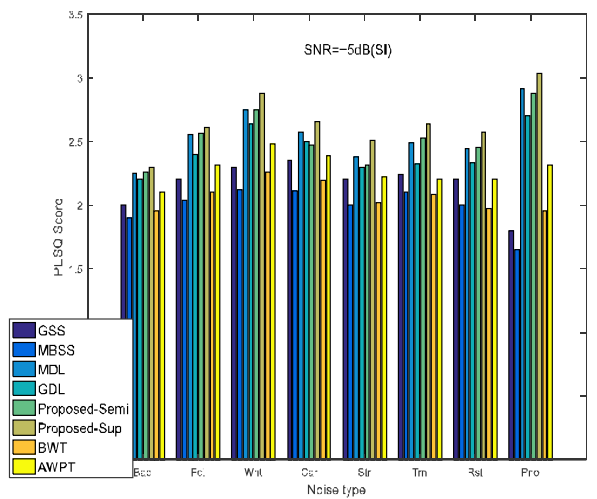

(c)

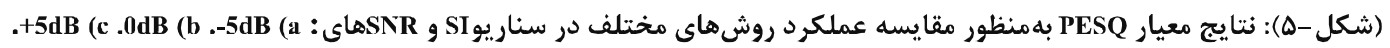
(Figure -5): Performance evaluation of different methods using PESQ score in speaker independent case (SI). a) SNR = -5dB, b) SNR = $0 \mathrm{~dB}$ and c) $\mathrm{SNR}=+5 \mathrm{~dB}$.

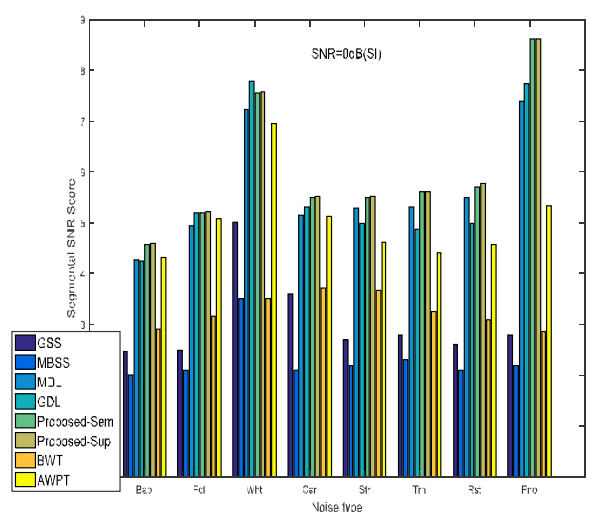

(b)

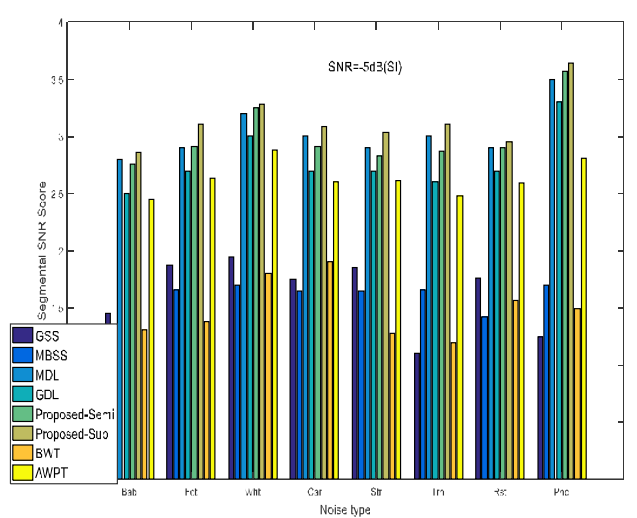

(a)

سال 


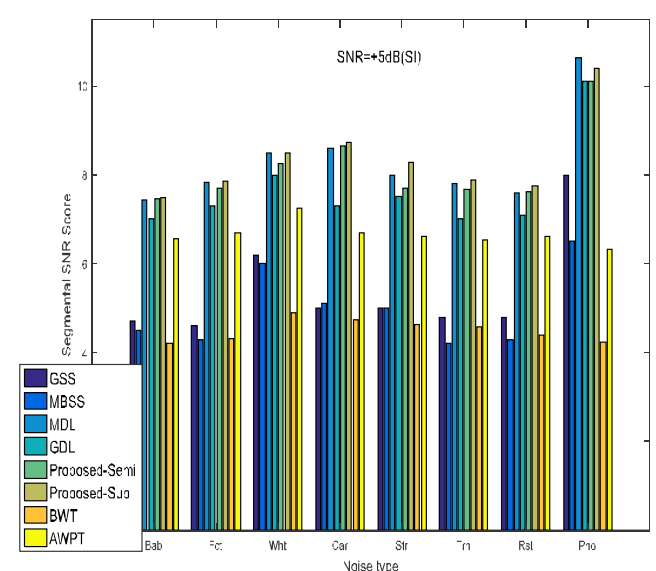

(c)

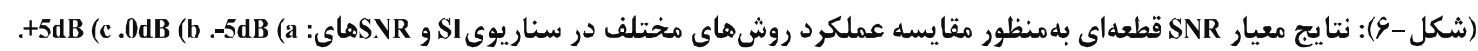
(Figure-6): Performance evaluation of different methods using frequency weighted segmental SNR value in speaker independent case (SI). a) $\mathrm{SNR}=-5 \mathrm{~dB}, \mathrm{~b}) \mathrm{SNR}=0 \mathrm{~dB}$ and c) $\mathrm{SNR}=+5 \mathrm{~dB}$.

موسيقى بهترين مقادير و در حضور نوفهاى با نايستايى

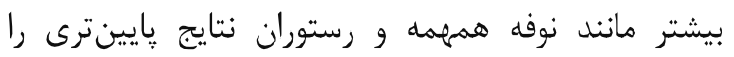

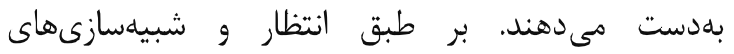

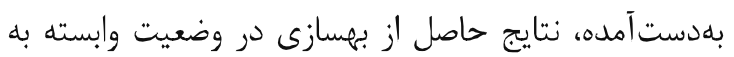

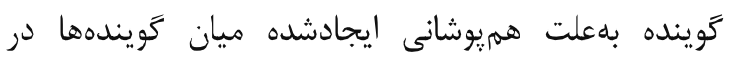

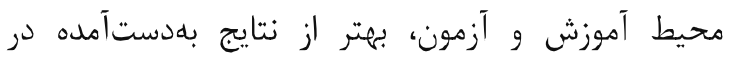
وضعيت مستقل از گوينده خواهد بود.
همجنين ميانگَين نتايج بر روى تمامى شرايط نوفهاى

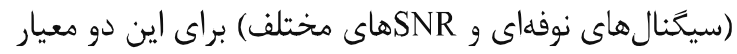

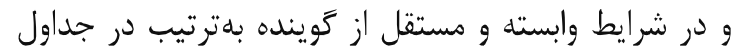

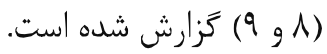

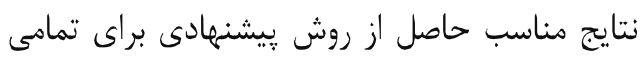

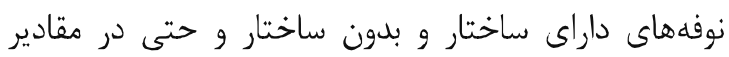
SNR

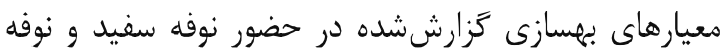

(جدول-F) نتايج معيار PESQ بهنظور مقايسه عملكرد روش هاى مختلف در سناريوى SI. نتايج روش بيشنهادى در وضعيت بانظارت و و

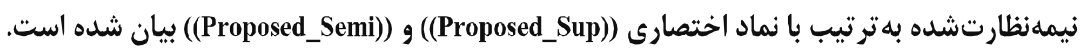

(Table-4): The results of PESQ measure values for performance evaluation of different methods in the presence of the mentioned noise signals in SI scenario. The proposed method is introduced using ((Proposed_Sup)) and ((Proposed_Semi)) in supervised and semi supervised situations, respectively.

\begin{tabular}{|c|c|c|c|c|c|c|c|c|c|c|c|c|c|c|c|c|}
\hline \multicolumn{8}{|c|}{$\mathrm{SNR}=-\Delta$} & \multicolumn{8}{|c|}{$\mathrm{SNR}=+\Delta$} & \\
\hline$\tilde{w}$ & 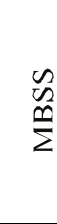 & $\vec{z}$ & Оิ & 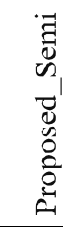 & 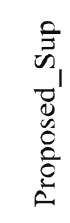 & 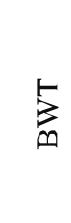 & $\sum_{4}^{5}$ & $\begin{array}{l}\tilde{D} \\
0 \\
0\end{array}$ & $\begin{array}{l}\tilde{n} \\
\hat{n}\end{array}$ & $\bar{\Sigma}$ & 号 & $\begin{array}{l}\tilde{\Xi} \\
0 \\
w \\
0 \\
0 \\
0 \\
0 \\
0 \\
0 \\
0 \\
0\end{array}$ & 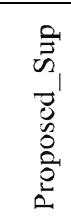 & 5 & $e_{4}^{\circ}$ & \\
\hline $1 / 1$. & .199 & $1 / \pi N$ & $1 / \Gamma \Delta$ & $1 / 4 \lambda$ & $1 / \Delta \Delta$ & $1 / \cdot 9$ & $1 / r$. & $r$ & 1/9. & $r / r$. & $r / 11$ & T/YG & $r / \mu$. & 1/9. & $r / l$. & هoهم \\
\hline $1 / 14$ & $1 / 10$ & $1 / 4$. & $1 / r r$ & $1 / 4 \Delta$ & $1 / 91$ & $1 / 1$. & $1 / \pi \Lambda$ & $r / T$. & $T / \cdot F$ & $r / 4 q$ & T/RF & $T / \Delta S$ & $r / 9 \mid$ & $r / 1$. & $r / T 1$ & كارخانه \\
\hline $1 / r \pi$ & $1 / 19$ & $1 / 44$ & $1 / \% 1$ & $1 / \Delta r$ & $1 / 9$. & $1 / \pi r$ & $1 / \pi r$ & $T / K$. & $T / M$ & $r / 89$ & $r / 4 F$ & r/VD & $r / A \Lambda$ & T/KS & $r / \& \Lambda$ & سفيد \\
\hline $1 / T F$ & $1 / 14$ & $1 / 45$ & $1 / T^{K}$ & $1 / 49$ & $1 / \Delta V$ & $1 / 14$ & $1 / T V$ & r/Ka & $r / 11$ & $r / f \Delta$ & $r / \% \Lambda$ & $Y / F V$ & $r / 98$ & $r / 19$ & $r / 49$ & ماشين \\
\hline $1 / \pi r$ & $1 / 1 \%$ & $1 / \pi \Lambda$ & $1 / 41$ & $1 / 4 \mathrm{~F}$ & $1 / \Delta \Delta$ & $1 / 1 \Lambda$ & $1 / \pi 4$ & $r / \pi$. & $T / \theta$ & $r / \mu$ & T/TV & $r / 41$ & $r|\Delta|$ & $r / . r$ & $r / \pi r$ & خيابان \\
\hline$|/ r|$ & $1 / 11$ & $1 / 4 \mid$ & $1 / \pi r$ & $1 / 4 \wedge$ & $1 / \Delta F$ & $1 / 19$ & $1 / \pi r$ & $T / K F$ & $r / l$. & $T / A T$ & T/KT & $r / \Delta T$ & $r / 94$ & $r / \cdot \Lambda$ & $r / \pi$. & قطار \\
\hline $1 / 1$. & 1 & $1 / 4$. & $1 / 49$ & $|/ \Delta|$ & 1/AT & $1 / N r$ & $1 / \pi \Lambda$ & $r / l f$ & $r$ & $r / r q$ & T/KT & $r / F \Delta$ & $T / \Delta V$ & 1/9v & $r / / \Lambda$ & رستوران \\
\hline $1 / \pi N$ & $1 / 19$ & $1 / \Delta r$ & $1 / 49$ & $1 / \Delta \Delta$ & $1 / 8 \mathrm{~V}$ & $1 / 1 \Lambda$ & $1 / 41$ & $1 / 1$. & 1,90 & $r / A r$ & $r / 9 D$ & $\Gamma / \mathcal{M}$ & $r /+r$ & $1 / 90$ & $r / \pi 1$ & يبيانو \\
\hline
\end{tabular}


(جدول - (D): نتايج معيار SNR قطعهاى به منظور مقايسه عملكرد روش هاى مختلف در سناريوى SI. نتايج روش بيشنهادى در وضعيت

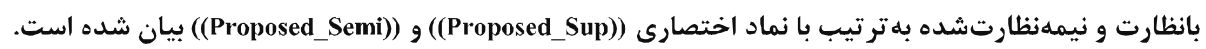

(Table-5): The results of frequency weighted segmental SNR values for performance evaluation of different methods in the presence of the mentioned noise signals in SI scenario. The proposed method is introduced using ((Proposed_Sup)) and ((Proposed_Semi)) in

\begin{tabular}{|c|c|c|c|c|c|c|c|c|c|c|c|c|c|c|c|c|}
\hline \multicolumn{8}{|c|}{$\mathrm{SNR}=-\Delta$} & \multicolumn{8}{|c|}{$\mathrm{SNR}=+\Delta$} & \\
\hline$\tilde{D}$ & ${ }_{n}^{\infty}$ & $\overrightarrow{\mathrm{i}}$ & $\overrightarrow{0}$ & 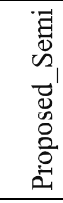 & 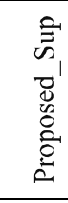 & 文 & $\sum_{4}^{n}$ & $\tilde{0}$ & 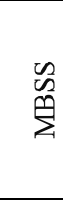 & $\overline{\mathrm{e}}$ & 官 & 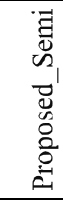 & 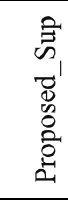 & $\stackrel{F}{\stackrel{5}{m}}$ & $\sum_{4}^{5}$ & \\
\hline $1 / F \Delta$ & $1 / \pi \Delta$ & $r / \Lambda$. & $r / \omega$. & $T / V G$ & r/AS & $1 / \pi 1$ & $T / F D$ & $F / V$. & $r / \Delta$. & $V / F T$ & $v$ & $V / \uparrow q$ & $V / F \wedge$ & $r / r$. & $S / D S$ & dapas \\
\hline I/AV & $1 / 94$ & $r / 9$. & $T / V$. & $T / 9)$ & $r / 11$ & $1 / \pi \wedge$ & T/QT & $F(9)$ & $K / \mu r$ & VIAY & $V / r$. & $V / \& 9$ & V/A & F/TY & $9 / V I$ & كارخانه \\
\hline $1 / 90$ & $1 / V$ & $r / T \cdot$ & $r$ & TrS & $r / r \wedge$ & $1 / \lambda$. & $r / \Lambda \Lambda$ & $4 / T 1$ & $81 . r$ & $\Lambda / F T$ & $\Lambda / \cdot r$ & $N / T \Delta$ & $\Lambda / \Delta$. & $4 / 19$ & $V / r \Delta$ & سفيد \\
\hline $1 / N Q$ & $1 / 90$ & $r$ & $T / V$. & $T / 91$ & $r 1.9$ & $1 / 9$. & $T / 9$. & $\Delta / \cdot T$ & $\Delta / /$. & $1 / 9$. & $V / r$. & N/9D & $\Lambda / V \psi$ & F/vo & $9 / 91$ & ماشين \\
\hline $1 / \wedge \Delta$ & $1 / 90$ & $r / 9$. & $r / V$. & $r / \Lambda r$ & $r / . r$ & $1 / r \wedge$ & $r|q|$ & $\Delta / \cdot 9$ & $\Delta / \cdot \wedge$ & $\Lambda / \cdot F$ & $V / \Delta Y$ & $V / 99$ & $V / T \Lambda$ & F/gY & $8|8|$ & خيابان \\
\hline $1 / 1$. & $1 / 99$ & $r$ & $T / 4$. & T/AV & $r / 11$ & $1 / 19$ & $T / F A$ & $F / A)$ & $F / T T$ & V/AT & $V / \cdot T$ & $V / \& \Lambda$ & $V / 19$ & $f / 0 q$ & $g / D F$ & قطار \\
\hline I/V9 & $1 / F Y$ & $r / 9$. & $T / V$. & $r / 9$. & $r / 9 \Delta$ & $1 / \Delta 9$ & $r / 69$ & $F(A)$ & $F / T r$ & $V|\&|$ & $V / 1 Y$ & VIGY & $v / v \Delta$ & $f / 4 r$ & $4 / 94$ & رستوران \\
\hline $1 / T \Delta$ & $1 / v$. & $r / \Delta \cdot$ & $r / r$. & $r / \Delta V$ & r/sf & $1 / 49$ & $r|\Lambda|$ & $N / \cdot 9$ & g/Dr & $1 . / 1$ & $1 \cdot 11$ & 1.11 & $1 \cdot / 4$ & F/r & G/KK & קֶيانو \\
\hline
\end{tabular}

(جدول -9): نتايج معيار PESQ بهمنظور مقايسه عملكرد روشهاى مختلف در سناريوى SD. نتايج روش ييشنهيادى در وضعيت بانظارت و

نيمهنظارت شده به تر تيب با نماد اختصارى (Proposed_Sup)()) و (Proposed_Semi) بيان شده است.

(Table-6): The results of PESQ measure values for performance evaluation of different methods in the presence of the mentioned noise signals in SD scenario. The proposed method is introduced using ((Proposed_Sup)) and ((Proposed_Semi)) in supervised and semi

\begin{tabular}{|c|c|c|c|c|c|c|c|c|c|c|c|c|c|c|c|c|}
\hline \multicolumn{8}{|c|}{$\mathrm{SNR}=-\Delta$} & \multicolumn{8}{|c|}{$\mathrm{SNR}=+\Delta$} & \\
\hline$\tilde{0}$ & $\begin{array}{l}\tilde{N} \\
\tilde{N}^{n}\end{array}$ & $\overrightarrow{\mathrm{i}}$ & О & 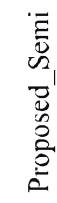 & 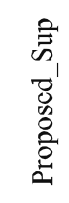 & $\sum_{m}^{5}$ & 崔 & $\tilde{b}$ & $\begin{array}{l}\Omega \\
\tilde{N} \\
\sum\end{array}$ & $\overrightarrow{\bar{\Sigma}}$ & $\overrightarrow{0}$ & 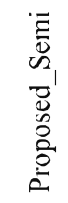 & 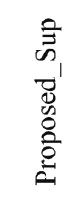 & 竞 & $\stackrel{5}{k}$ & \\
\hline $1 / 1$. &.$/ 99$ & $1 / 49$ & $1 / r r$ & $1 / 01$ & $1 / \Delta \Lambda$ & $1 / \cdot 9$ & $1 / \pi$. & $r$ & $1 / 9$. & $r / \Gamma$. & $r / 19$ & र/ץq & $T / T V$ & $1 / 90$ & $r / 1$. & daftas \\
\hline $1 / 1 r$ & $1 / 1 \Delta$ & $1 / 49$ & $1 / F Y$ & $1 / \Delta r$ & $1 / \& T$ & $1 / 1$. & $1 / \pi \Lambda$ & $T / T$. & $r / \cdot F$ & $r / \Delta \&$ & $r / Y$ & $r / \Delta q$ & $r / \& q$ & $r / 1$. & $r / r)$ & كارخانه \\
\hline I/Tr & $1 / 19$ & $1 / \Delta F$ & $1 / 4 V$ & $1 / 9$. & $1 / 99$ & $1 / 1 \%$ & r & $T / T \cdot$ & $r / 1 r$ & $T / V \Delta$ & $r / q q$ & $r / \Lambda \cdot$ & $r / \wedge \Lambda$ & $T / T G$ & $r / \digamma \Lambda$ & سفيد \\
\hline $1 / T r$ & $1 / 14$ & $1 / \Delta T$ & $1 / f \Delta$ & $1 / 01$ & $1 / 94$ & $1 / 1 F^{r}$ & $1 / \pi V$ & $r / T \Delta$ & $r / 11$ & $r / \Delta S$ & $r / \uparrow q$ & $r / Q 9$ & r/VT & $5 / 19$ & $r / \pi q$ & ماشين \\
\hline $1 / T Y$ & $1 / 1 Y$ & $1 / 44$ & $1 / 4$. & $1 / \Delta \Delta$ & I/ET & $1 / 1 \wedge$ & $1 / \pi 4$ & T/T. & $r / D$ & $r / F \Delta$ & $r / T \omega$ & $r / \omega \cdot$ & $r / \Delta \&$ & $r / T$ & Y/TY & خيابان \\
\hline $1 / \pi 1$ & $1 / 11$ & $1 / \Delta \cdot$ & $1 / 4 F$ & $1 / \Delta r$ & $1 / \Delta 9$ & $1 / 19$ & $1 / \pi r$ & $T / T F$ & $r / 1$. & T/QT & $r / F$. & $T / \Delta \Lambda$ & $r / 9 q$ & $r / \cdot \Lambda$ & $T / T \cdot$ & قطار \\
\hline $1 / 1$. & 1 & $1 / 4 \lambda$ & $1 / T V$ & $1 / \Delta r$ & $1 / \Delta V$ & $1 / 1 T$ & $1 / \pi \Lambda$ & $T / I F$ & r & $T / T \Delta$ & $T / T V$ & $r / F \Lambda$ & $r / 9 F$ & 1/9V & $T / 1 \Lambda$ & رستوران \\
\hline $1 / r \Lambda$ & $1 / 18$ & $1 / 04$ & $1 / f \Delta$ & $1 / \Delta \Lambda$ & $1 / 8 \wedge$ & $1 / 1 \wedge$ & $1 / 41$ & $1 / 1$. & $1 / 8 \Delta$ & Y/A & r/9A & r/A & $r / . r$ & $1 / 9 \Delta$ & $Y / T I$ & بيانو \\
\hline
\end{tabular}

(جدول - (V): نتايج معيار SNR قطعهاى به منظور مقايسه عملكرد روشهاى مختلف در سناريوى SD. نتايج روش بيشنـيهادى در وضعيت

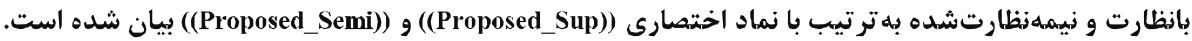

(Table-7): The results of frequency weighted segmental SNR values for performance evaluation of different methods in the presence of the mentioned noise signals in SD scenario. The proposed method is introduced using ((Proposed_Sup)) and ((Proposed_Semi)) in supervised and semi supervised situations, respectively.

\begin{tabular}{|c|c|c|c|c|c|c|c|c|c|c|c|c|c|c|c|c|}
\hline \multicolumn{8}{|c|}{$\mathrm{SNR}=-\Delta$} & \multicolumn{8}{|c|}{$\mathrm{SNR}=+\Delta$} & \\
\hline$\stackrel{2}{0}$ & $\begin{array}{l}\tilde{N} \\
\hat{\Sigma}\end{array}$ & $\stackrel{\vec{\rho}}{\Sigma}$ & 它 & 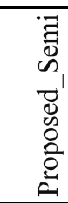 & 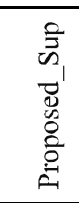 & $\stackrel{5}{\stackrel{m}{m}}$ & $\stackrel{5}{\stackrel{5}{k}}$ & $\begin{array}{l}\tilde{2} \\
\mathbb{O}\end{array}$ & $\begin{array}{l}\tilde{N} \\
\hat{n}\end{array}$ & $\stackrel{\vec{\rho}}{\Sigma}$ & 今ి & 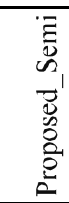 & 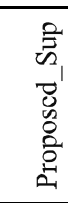 & 率 & $\stackrel{5}{\stackrel{5}{\xi}}$ & \\
\hline $1 / 4 \Delta$ & $1 / \pi \Delta$ & $r / q Y$ & $r / \Delta V$ & $r / . q$ & $r / 1 \Lambda$ & $1 / \pi 1$ & $T / F \Delta$ & $\varphi / v$. & $\varphi / \Delta$. & $V / \Delta \Lambda$ & $V / T r$ & $V / \Delta F$ & $V / 94$ & $r / r$. & $\varepsilon / \Delta \varphi$ & هميمه \\
\hline I/AV & $1 / 99$ & $r / l l$ & $r / V \cdot$ & $r / N F$ & $r / T$. & $1 / \mu \wedge$ & r/q & $4 / 91$ & f/RT & $V / 91$ & $V / F \Delta$ & $8 / 99$ & $A /+r$ & f/Nr & $\Lambda / v 1$ & كارخانه \\
\hline
\end{tabular}




\begin{tabular}{|c|c|c|c|c|c|c|c|c|c|c|c|c|c|c|c|c|}
\hline $1 / 90$ & $1 / V$ & YMI & $r$ & r/rA & $r / r v$ & $1 / 1$. & r/Aג & $8 / T)$ & $81 \cdot r$ & NISY & N/TY & N/\&\& & $\Lambda / \vee q$ & $4 / \wedge q$ & $V / T \Delta$ & سفيد \\
\hline $1 / V \Delta$ & $1 / 80$ & $r / I V$ & $r / 9 Y$ & $r / T r$ & $r / r q$ & $1 / 9$. & $r / s$. & $\Delta / \cdot r$ & $\Delta / 1$. & $N / \& q$ & $V / 4)$ & $N / V 1$ & $\Lambda / V G$ & $F / V \Delta$ & $s / \& \wedge$ & ماشين \\
\hline $1 / 1 \Delta \Delta$ & $1 / 90$ & $r / 19$ & $r / \Lambda \Lambda$ & $\Gamma / \Lambda$ & $r / T H$ & $1 / r \lambda$ & $1 / 95$ & $\Delta / \cdot \varphi$ & $\Delta / \cdot 1$ & $\Lambda / \mu I$ & V/gr & N/rG & $\Lambda / \uparrow \Lambda$ & f/gT & $9 / 91$ & خيابان \\
\hline $1 / 1$ & $1 / 99$ & $r / l$ & $r / v \Delta$ & $r / . q$ & r/rr & $1 / 19$ & $r / F_{\Lambda}$ & $F|\Lambda|$ & F/T & $V / \wedge q$ & V/rr & $V / q 1$ & $\Lambda / \cdot 1$ & $f / \Delta q$ & $s \mid \Delta F$ & قطار \\
\hline I/V9 & $1 / 4 T$ & $r / \cdot V$ & $r / 9 \mid$ & $\Gamma / \cdot \Lambda$ & $r / l \Delta$ & $1 / \Delta \varphi$ & T/D9 & $f(\lambda)$ & F/TT & $V / V \Delta$ & V/ra & $V / \Lambda$. & V/Aq & f/fr & G/GT & رستوران \\
\hline $1 / 7 \Delta$ & $1 / V$ & r/AF & $r(\Delta)$ & M/4, & $r / v q$ & $1 / 49$ & $r|\Lambda|$ & $N \cdot G$ & G/DT & $1+19$ & $1 \cdot \pi$ & $1 \cdot 10$ & $1 \cdot 19$ & $F / Y Y$ & G/TH & بيانو \\
\hline
\end{tabular}

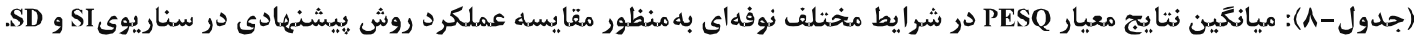
(Table-8): The average results of PESQ score of the proposed method in SI and SD scenarios in the presence

\begin{tabular}{|c|c|c|c|c|c|c|c|c|c|}
\hline \multicolumn{8}{|c|}{ mentioned $\mathbf{n}$} & & \\
\hline GSS & MBSS & MDL & GDL & Proposed_Semi & Proposed_Sup & BWT & AWPT & & \\
\hline $1 / 9 V$ & $1 / \Delta \Delta$ & $1 / 90$ & $1 / 18$ & $1 / 9.9$ & $r / .9$ & $1 / 9$. & $1 / v 9$ & SD & \multirow{2}{*}{ PESQ } \\
\hline $1 / 9 \mathrm{~V}$ & $1 / \Delta \Delta$ & $1 / 19$ & $1 / 79$ & $1 / \Lambda \Lambda$ & $r / \cdot 1$ & $1 / 9$. & $1 / \sqrt{ } 9$ & SI & \\
\hline
\end{tabular}

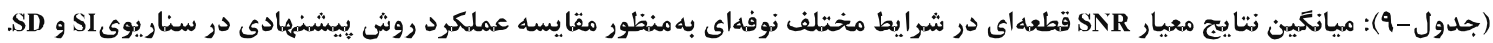
(Table-9): The average results of frequency weighted segmental SNR values of the proposed method in SI and SD scenarios in the presence of the mentioned noise signals.

\begin{tabular}{|c|c|c|c|c|c|c|c|c|c|}
\hline GSS & MBSS & MDI & GDL & Proposed_Semi & Proposed_Sup & BWT & AWPT & & \\
\hline$r|\Delta|$ & $r / r$. & $r / f F$ & $r / \pi)$ & r/ar & $\notin / \varepsilon \Delta$ & $r / T$. & $F / . q$ & SD & \multirow{2}{*}{ PESQ } \\
\hline$r|\Delta|$ & r & $r / \mu$. & $f / 1 \varphi$ & $f / \mu \omega$ & $F / F V$ & $r / r$. & $4 / .9$ & SI & \\
\hline
\end{tabular}

(جدول -+1): نتايج معيار PESQ و SNR قطعهاى در سناريوى SI به منظور مقايسه عملكرد روش بيشنههادى در وضعيت نيمهزظارتشده، روش

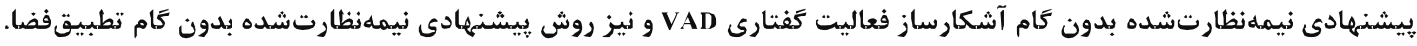

(Table-10): The results of PESQ and frequency weighted segmental SNR measures in SI scenario for performance evaluation of the proposed semi supervised method, the proposed semi supervised method without VAD step, and the proposed semi supervised method

\begin{tabular}{|c|c|c|c|c|c|c|c|c|c|c|}
\hline بيانو & رستوران & قطار & خيابان & ماشين & سفيد & كارخانه & همبرمه & & & \\
\hline r/AA & $r / F Q$ & $r / \Delta r$ & $r / r \mid$ & $r / F V$ & $r / V \Delta$ & $r / \Delta \varphi$ & T/Tr & $+\Delta$ & \multirow{2}{*}{ PESQ } & \multirow{4}{*}{ Proposed_Semi } \\
\hline $1 / \Delta \Delta$ & $1 / \Delta 1$ & $1 / F A$ & $1 / F F$ & $1 / 4 q$ & $1 / \Delta r$ & $1 / F \Delta$ & $1 / F \wedge$ & $-\Delta$ & & \\
\hline $1 . / 1$ & VI\&Y & $V / \& \wedge$ & $V / 8 q$ & $\Lambda / \& \Delta$ & $\Lambda / T \Delta$ & $V / 89$ & $V / f q$ & $+\Delta$ & \multirow{2}{*}{ SegSNR } & \\
\hline$r / \Delta V$ & $r / q$. & r/AV & r/Ar & $r / 91$ & r/TA & $r / q 1$ & r/VE & $-\Delta$ & & \\
\hline r/rq & T/19 & $r / T$ & $r / \cdot V$ & $r / T$ & $r / \varphi$. & $r / \bullet$ & $1 / 91$ & $+\Delta$ & \multirow{2}{*}{ PESQ } & \multirow{4}{*}{$\begin{array}{l}\text { Proposed_Semi } \\
\text { VAD بدون }\end{array}$} \\
\hline $1 / 79$ & $1 / \pi 1$ & $1 / 11$ & $1 / 10$ & $1 / 1 \mathrm{~V}$ & $1 / \pi V$ & $1 / 1 \pi$ & $1 / 11$ & $-\Delta$ & & \\
\hline १/А९ & $V / T 1$ & $V / r q$ & V/r/ & $V / \Gamma 1$ & V/৭A & $\mathrm{V} / \mathrm{rA}$ & $9 / 99$ & $+\Delta$ & \multirow{2}{*}{ SegSNR } & \\
\hline$r / 4 i$ & $r / \Delta \mid$ & $r / F F$ & $r / \Delta \mid$ & $r / 9 T$ & $r / l F$ & $\Gamma / \& \wedge$ & T/K & $-\Delta$ & & \\
\hline$T / M I$ & $r / r \Lambda$ & $r / T \Delta$ & $T / / F$ & $t / 4 r$ & r/\&६ & $T / T V$ & $T / \cdot F$ & $+\Delta$ & \multirow{2}{*}{ PESQ } & \multirow{4}{*}{$\begin{array}{c}\text { Proposed_Semi } \\
\text { بدون كامبيقفضا }\end{array}$} \\
\hline $1 / 4 \lambda$ & $1 / T r$ & $1 / r r$ & $1 / r T$ & $1 / F F$ & $1 / 4 \lambda$ & $1 / T T$ & $1 / \pi 9$ & $-\Delta$ & & \\
\hline $9 / 97$ & $V / F A$ & $V / F F$ & V/FT & $V / F D$ & $1 / \cdot 9$ & $V / T \Delta$ & $\mathrm{V} / \backslash \Lambda$ & $+\Delta$ & \multirow{2}{*}{ SegSNR } & \\
\hline$r / 4 q$ & T/\& & $r / \Delta \varphi$ & $r|8|$ & $T / V F$ & $r / r$. & T/VV & $r / \Delta \cdot$ & $-\Delta$ & & \\
\hline
\end{tabular}

(·) بيان شده است. همانطوركه از اين نتايج هشخص است، اين دو گام و بهخصوص استفاده از گام آشكارسازى لئى فعاليت كفتارى ييشنهادى بهطور محسوسى در دستيابى به نتايج مطلوب مؤثر خواهد بود. همانطوركد از نتايج حاصل مشاهده مىشود، تأثير روش تطبيق فضا در دستيابى به نتايج حاصل زيز هحسوس است و استفاده از اين روش مناسب وضعيتى خواهد بود كه يك وازمنامه نوفه اوليه در دسترس باشد. همجنين مى توان مشاهده كرد كه تأثير اين دو كام در حضور نوفه داراى ايستايى بيشتر مانند نوفه
بهمنظور بررسى عملكرد بخشهاى هختلف الكوريتم

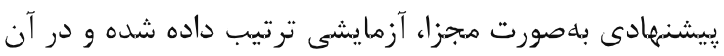

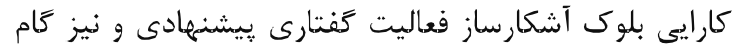
تطبيق فضاى بلكار گرفته شده مورد ارزيابى قرار گرفته است. در اين شبيهسازى، نتايج معيار PESQ و PNR قطعهاى در در سناريوى SI بهمنظور هقايسه عملكرد روش ريشنهادى در وضعيت نيمهنظارتشده، روش بيشنهادى نيمهنظارتشده

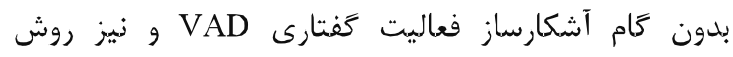
يبيشنهادى نيمهنظارتشده بدون گام تطبيقفضا در جدول 
بهسازى گفتتار در فضاى تبديل موجك با تخمين نوفه بهروزشونده AWPT، بهعلت استفاده از مدلهاى ناهمدوس براى مؤلفههاى داده ورودى نتايج بهترى را به دست مى دهد. در ادامه بهمنظور تصميمزيرى دقيق در مورد كارايى مونى روشهاى مختلف مورد بررسى در شرايط متنوع يادشده، آزمون معنادارى آمارى به كاركرفته شده است. در اين مقاله

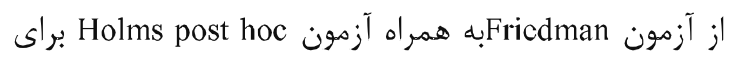

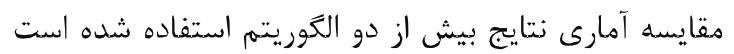

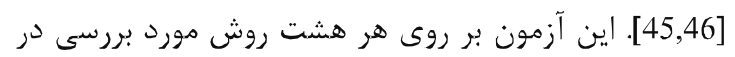
شكلها و جداول بخش شبيهسازى و در حضور هشت نوع سيخنال نوفه، سه دقدار مورد وضعيت SI و SD انجام مىشود؛ بنابراين در اين آزمون، تعداد روشها و شرايط مختلف بهترتيب J=人 و I I I است. كفتنى است كه هر جهه تعداد شرايط در مقايسه با تعداد روشها بيشتر باشد، نتايج مناسبترى حاصل مىشود. آزمون Fricdman هقايسه هند روش در هجموعه شرايط گَوناگون است و به فرضيات اوليه نياز ندارد. بهعنوان مرور كلى بر روال اين آزمون فرض مى كنيم كه زR ميانخين رتبه عملكرد براى ز

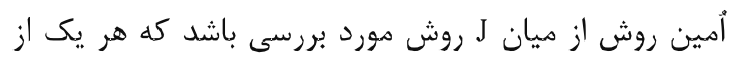

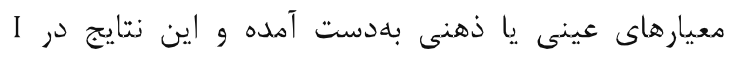
شرايط مختلف صورت يذيرفته باشد:

$R_{j}=\frac{1}{I} \sum_{i=1}^{I} r_{i j}$

كه در آن rij رتبه عملكرد ز-أمين روش در وضعيت i-ام آزمون خواهد بود. الكَوريتم با بهترين عملكرد در اين آزمون، كمترين مقدار رتبه را خواهد داشت. آزمون معنادار آهارى با اين فرضيه يوج ' كه همه الخَوريتهمها كارايى يكسان دارند شروع به كار مىكند [47]. با استفاده از آزمون آمارى Friedman يذيرفته مىشود. اين آزمون بهصورت زير بررسى مىشود: $\chi_{F}^{2}=\frac{12 I}{J(J+1)}\left[\sum_{j=1}^{J} R_{j}^{2}-\frac{J(J+1)^{2}}{4}\right]$

همجنهين آمار اصلاحشده از آزمون Friedman كه

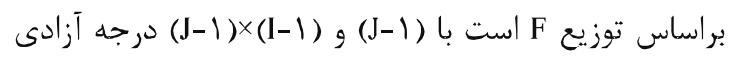

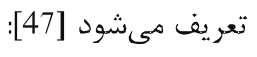

${ }^{2}$ Null-hypothesis
سفيد، يريوديك و ييانو بسيار كمتر از ساير نوفههاى داراى

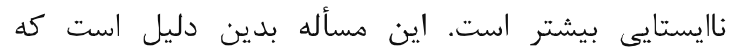
نوفههاى سفيد و ييانو بهعلت دارابودن ايستايى مناسب بئن خوشساختار بوده و با همان وازهنامه آموزشديده اوليد

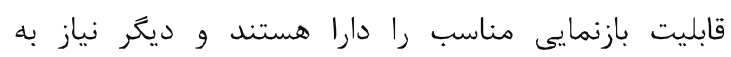
بلروزرسانى اتمها بر طبق شرايط محيط آزمون وجود ندارد زيرا شرايط محيط آموزش و نويز در مورد اين دسته نوفهها داراى شباهت بيشترى خواهد بود. نوريط.

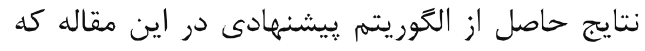

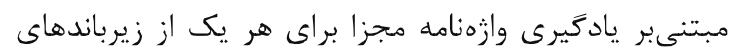
تقريب و جزئيات است، در سناريوى نظارتشده بهتر از نتايج ساير روشها بوده است. همجنين نتايج حاصل از سناريوى نيمهنظارتشده نيز اندكى كمتر از سناريوى نظارتشده است. اين برترى مىتواند بددليل بازنمايى هر قاب مشاهده

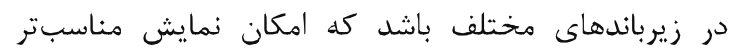
هحتواى سيخنال را بهدست مى دهد. اين نتايج براى انواع نوفه ساختاريافته، متناوب و بدون ساختار قابل تعميمم است؛

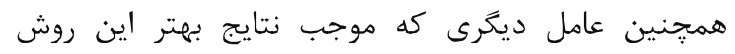
نسبت به ساير روشها مىشود، تخمين نوفهاى است كد در

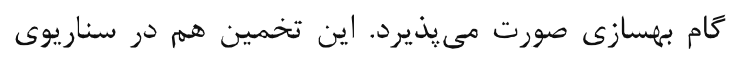
نظارتشده و هم نيمهنظارتشده انجام مىشود. در سناريوى نظارتشده يس از بهروزرسانى اتمهاى وازمنامه نوفه براساس

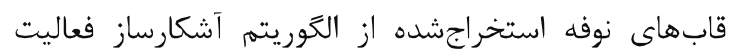

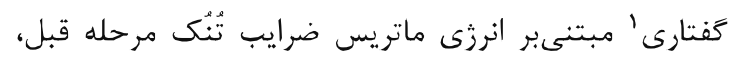
شرايط نوفهاى فضاى آموزش به فضاى آزمون نزديكتر شده و اتمهاى نوفه بازنمايى درستى از شرايط محيط در كام

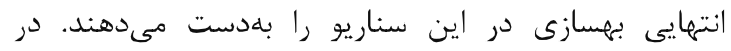
سناريوى نيمهنظارتشده نيز با توجه به تخمين قاب به قاب رينا نوفه با توجه به رابطه (IV) و تعيين مقدار آستانه و تابع

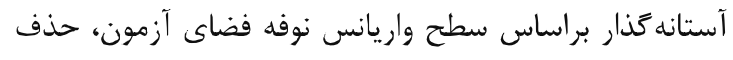
نوفه با توجه به شرايط نوفهاى محيط آزمون انجام مى در روش MDL كه مبتنى بر يادكيرى وازمنامه است، از باز وازهنامههاى نوفه يادكيرىشده در كام آموزش بهصورت مستقيم در كام بهسازى استفاده مىشود. در اين روش بلعلت عدم انطباق شرايط نوفهاى در محيط آموزش و آزمون

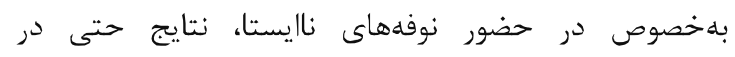
سناريوى نيمهنظارتشده، يايينتر از روش ارائهشده در اين مقاله خواهد بود؛ همجنين روش ييشنهادى نسبت به روش

${ }^{1}$ Voice activity detector (VAD) 
مقايسه اين نتايج مشخص مى شود كه تمامى مقادير

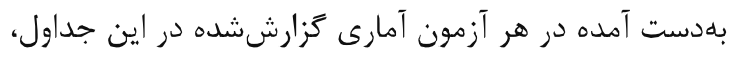
بيشتر از مقدار F بحرانى است؛ بنابراين بر طبق آندار آزمون

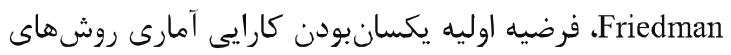

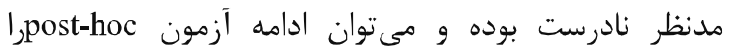
بهمنظور تعيين رتبه كارايى روشها دنبال كرد. همانطوركه

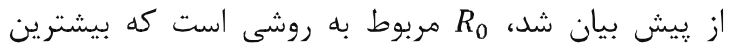

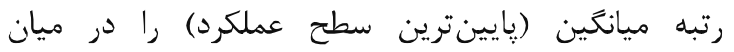
روشهاى مختلف دارد كه در بررسىهاى انجامشده متعلق به روش BWTست كه به الكوريته پِايه بهسازى كَفتار مبتنى بر تبديل موجك مى يردازد. بهمنظور محاسبه يارامتر

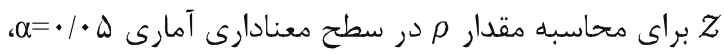

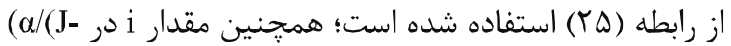

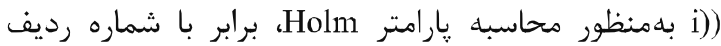

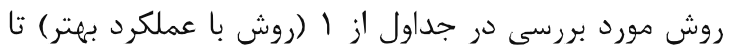

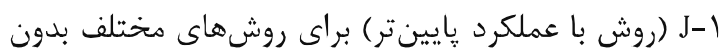

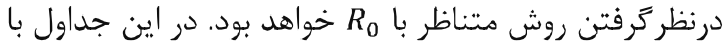
توجه به اينكه مقدار م براى تمامى روش رشها، كمتر از مقدار

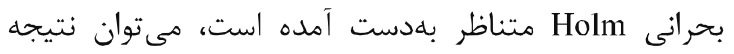
كرفت كه روشهاى مورد بررسى بلهترتيب قرار كرفته شده در جدول، از روش با بهترين عملكرد تا روش با بدترين

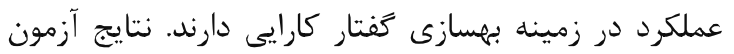

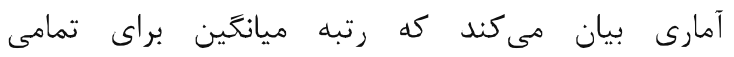

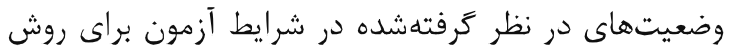
بيشنهادى نظارتشده، نزديك به يكى بوده كه موجب مىشود اين روش در جداول (|l و r||) در بالاترين رديف

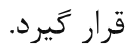

$F_{F}=(I-1) \chi_{F}^{2} /\left(I(J-1)-\chi_{F}^{2}\right)$

در اين آزمون آمارى، اكر مقدار FF، بزركتر از مقدار

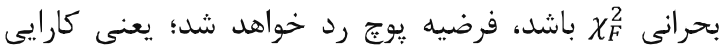

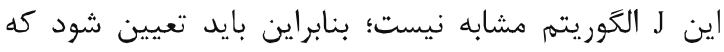

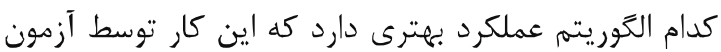

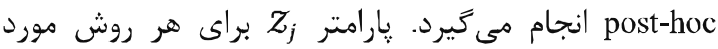

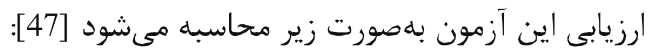

$Z_{j}=\left(R_{0}-R_{j}\right) / \sqrt{J(J+1) / 6 I}$

R مربوط به روشى است كه بيشترين رتبه

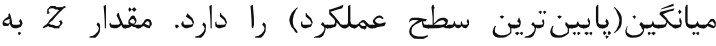

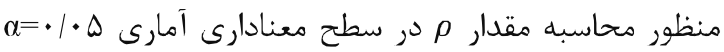

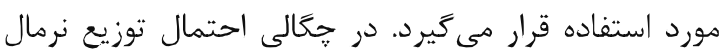
استاندارد، مقدار م متناظر با سطح زير اين توزيع و خارج از محدوده (Z,Z

$\rho=1-\int_{-Z}^{z} \frac{1}{\sqrt{2 \pi}} e^{-\frac{t^{2}}{2}} d t$

نتايج شبيهسازى با استفاده از آزمون آمارى براساس

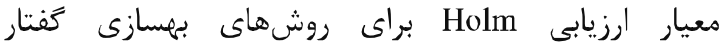
معرفى شده در تمامى شرايط نوفهاى با استفاده از معيارهاى PESQ

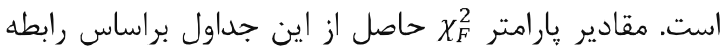

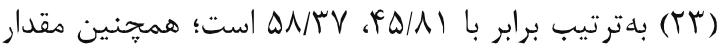

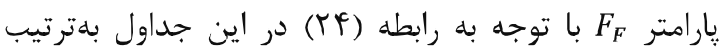

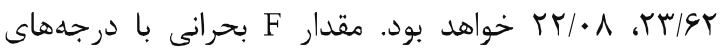

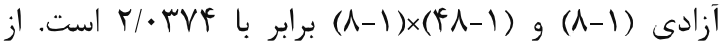

(جدول -1(): نتايج آزمون آمارى براى معيار PESQ در شرايط و نوفههاى مختلف.

(Table-11): The results of the statistical Friedman and Holm's post hoc test for PESQ score over different methods and conditions.

\begin{tabular}{|c|c|c|c|c|}
\hline Methods & Average $\operatorname{Rank}\left(\boldsymbol{R}_{\boldsymbol{j}}\right)$ & $z$ & $\rho$-value & $\operatorname{Holm}(\alpha /(J-i))$ \\
\hline Proposed_Sup & $1 / \pi \Lambda$ & $V(9)$ & . & $\cdot|\cdot v|$ \\
\hline Proposed_Semi & $1 / 91$ & $9 / f \wedge$ & • & $\cdot / \cdot \cdot \wedge r$ \\
\hline MDL & $r / T \Delta$ & $\Delta / f \mid$ & - & $.1 \cdot 1 \ldots$ \\
\hline GDL & r/9६ & F/r & - & $.1 .1 \mathrm{T \Delta}$ \\
\hline$\Lambda \mathbf{W P T}$ & $r / r$ & $F / T \Lambda$ & - & $.1 .19 \mathrm{~V}$ \\
\hline MBSS & $\mathrm{r} / \mathrm{gV}$ & r/Tr & (... & $.1 \cdot r \Delta$. \\
\hline GSS & $F / I T$ & $r / 1 \wedge$ & 厚 & $\cdot / \cdot \Delta \cdots$ \\
\hline $\operatorname{BWT}\left(R_{0}\right)$ & $r / T$ & - & - & 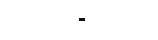 \\
\hline
\end{tabular}


(جدول-rا): نتايج آزمون آمارى براى معيار SNR قطعهاى در شرايط و نوفه هاى مختلف.

(Table-12): The results of the statistical Friedman and Holm's post hoc test for of frequency weighted segmental SNR values over different methods and conditions.

\begin{tabular}{|c|c|c|c|c|}
\hline Methods & Average Rank $\left(R_{j}\right)$ & $z$ & $\rho$-value & Holm $(\alpha /(J-i))$ \\
\hline Proposed_Sup & $1 / T F$ & N/TH & - & $\cdot|\cdot v|$ \\
\hline Proposed_Semi & $r / \cdot F$ & $9 / 91$ & - & . . • \\
\hline MDL & $r / \Delta \xi$ & Q/9T & - & $\cdot 1 \cdot 1 \cdot$. \\
\hline GI)L & TIAT & $\Delta / \mu \wedge$ & - & .1 .140 \\
\hline AWPT & $r / 1 r$ & p/qr & - & $.1 .19 \mathrm{~V}$ \\
\hline MBSS & r/VA & $r|q|$ & $\cdot \cdots r$ & . I. ra. \\
\hline GSS & $1 / T^{4}$ & $r / \& V$ & $\cdot / \cdot v \varepsilon$ & $\cdot / \cdot \Delta \cdot \cdot$ \\
\hline $\operatorname{BWT}\left(R_{0}\right)$ & $\Delta / \Delta T$ & - & - & - \\
\hline
\end{tabular}

تُنكى حاصل، قاب ورودى بازسازى مىشود. هر جقدر خطاى اين تقريب، ميان قاب مشاهدهشه و قاب بازسازىشده،

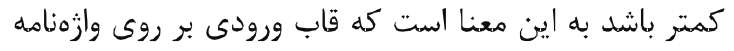

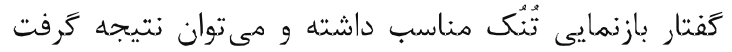

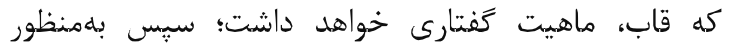

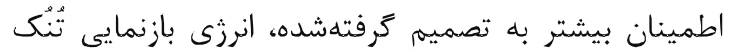

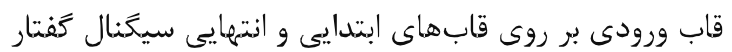

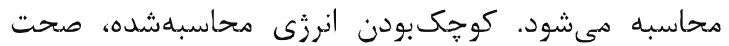

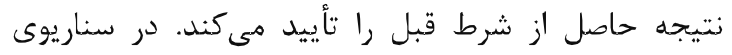

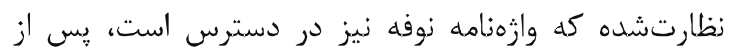

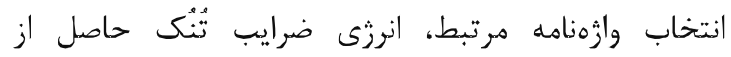

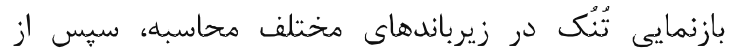

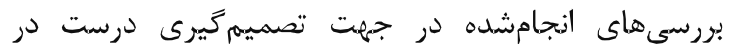
تعيين نوع قاب ورودى استفاده مىشود. در اداهه نتايج

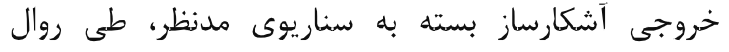

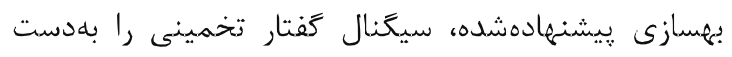
خواهد داد. نتايج كزارششده بر مبناى معيارهاى مورد بررسى، توانايى اين روش نسبت به ساير روشهاى بايه

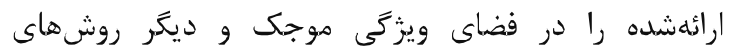

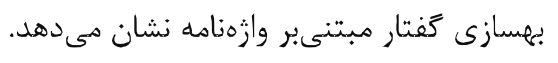

\section{6- References}

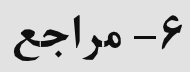

[1] M. Klein, P. Kabal, "Signal subspace speech enhancement with perceptual post-filtering", Proc. IEEE Internat. Conf. Acoust. Speech Signal Process. (ICASSP), Vol. 1, pp. 537-540, 2002.

[2] S. Kamath, P. Loizou, "A multi-band spectral subtraction method for enhancing speech corrupted by colored noise", In: Proc. IEEE Internat. Conf. Acoust. Speech Signal Process. (ICASSP), Orlando, Florida, 2002.
بنابراين مىتوان نتيجه كرفت كه روش زيشنمادى

نظارتشده در فضاى ويزگ

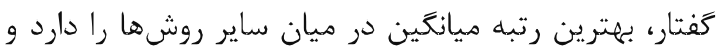

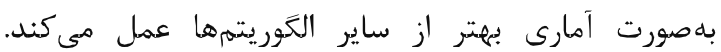

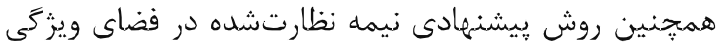
تبديل موجكى رتبه بعدى را به خود اختصاص مى دهدد. از آنجايى كه در اين جداول الكَوريته BWT با تابع آستانه كذارى نرم بهعنوان روش با ميانكين رتبه $R_{0}$ معرفى شده و مقدار

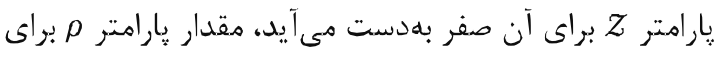

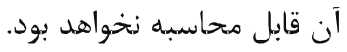

\section{ه- نتيجه}

در اين دقاله، يادگيرى وازمناهه بهمنظور دستيابى به دقت

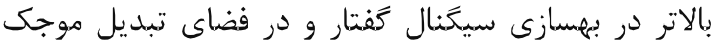
بررسى شده است. بهكمى اين تبديل، امكان تجزيه سيخنال

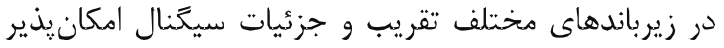
خواهد بود. تجزيه سيخنال به زيرباندها مىتواند إندات اطلاعات

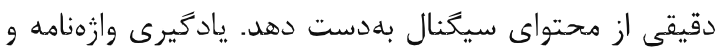

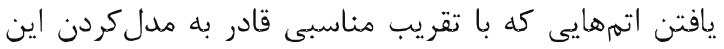

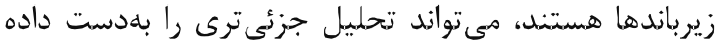

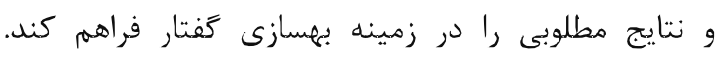
همجنين دو سناريوى نظارتشده و نيمهنظارتشده ارائه شد

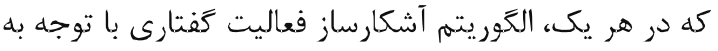
شرطهاى مخصوص به خود بر بايه محاسبه انرزى ضرايب

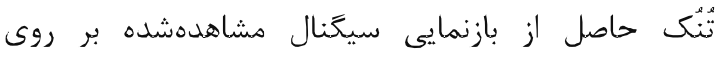

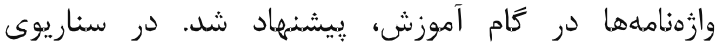

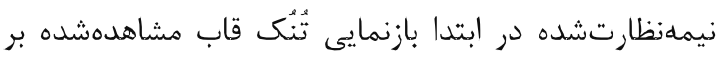

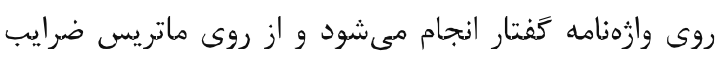


[16] M.A. Messaoud, A. Bouzid, "Speech enhancement based on wavelet transform and improved subspace decomposition", Journal of Audio Engineering society (JAES), Vol. 63, No.12, pp.1-11, 2015.

[17] C.L. Wu, H.P. Hsu, S.S. Wang, J.W. Hung, Y.H. Lai, H.M. Wang, Y. Tsao, "Wavelet speech enhancement based on robust principal component analysis", Proc. Interspeech, 781, pp. 439-443, 2017.

[18] T.Y. Zuo, L. He, W.D. Sheng, "A new algorithm of the wavelet packet speech denoising based on masking perception model", 7 th International conference on natural computation (ICNC), Vol. 1, 2011, pp. 33-37.

[19] H. Zhao, X. Peng, L. Hu, G. Wang, "An improved speech enhancement method based on teager energy operator and perceptual wavelet packet decomposition", Journal of Multimedia, Vol. 6, No. 3, 2011.

[20] R. Gomez, T. Kawahara, "Optimized waveletbased speech enhancement for speech recognition in noisy and reverberant conditions", APSIPA ASC, 2011.

[21] T.F. Sanam, C. Shahnaz, "Teager energy operation on wavelet packet coefficients for enhancing noisy speech using a hard thresholding function", Published in Signal Processing: An International Journal (SPIJ), Vol. 6, pp. 22-43, 2011.

[22] G. Chen, C. Xiong, J.J Corso, "Dictionary transfer for image denoising via domain adaptation", In Proceedings of IEEE International Conference on Image Processing, 2012.

[23] S. Mavaddati, S.M. Ahadi Sarkani, S. Seyedin, "A novel speech enhancement method by learnable sparse and low-rank decomposition and domain adaptation", Speech Communication, Vol. 76, pp. 42-60, 2016.

[24] A. Agarwal, A. Anandkumar, P. Jain, P. Netrapalli, R. Tandon, JMLR: Workshop and Conference Proceedings, Vol. 35, 2014, pp. 1 15.

[25] H. Lee, A. Battle, R. Raina, A.Y. Ng, "Efficient sparse coding algorithms", Advances in Neural Information Processing Systems, 2006.

[26] J. Portilla, L. Mancera, "L ${ }_{0}$-based sparse approximation: Two alternative methods and some applications", Proceedings of the 16th IEEE international conference on Image processing, 2009, pp. 3865-3868.

[TV] مودّتى، سميرا، احدى، محمد، "بهسازى كفتار به كمك

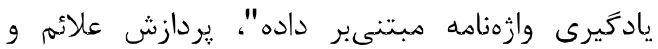

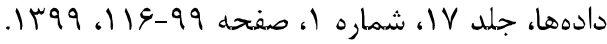

[3] D.L. Donoho, "De-noising by soft-thresholding", IEEE Trans. Inf. Theory, Vol. 41, No. 3, pp. 613$627,1995$.

[4] N. Upadhyay, R.K. Jaiswal, "Single Channel Speech Enhancement: Using Wiener Filtering with Recursive Noise Estimation", Procedia Computer Science, Vol. 84, pp. 22-30, 2016.

[5] J. Candes, M.B. Wakin, "An introduction to compressive sampling", IEEE Signal Processing Magazine, pp. 21-30, 2008.

[6] R.G. Baraniuk, "Compressive Sensing", IEEE Signal Processing Magazine, pp. 118-121, 2007.

[7] S. Ayat, R. Dianat, M. Manzuri, "Wavelet Based Speech Enhancement Using a New Thresholding Algorithm", IEEE Intl. Symposium on Intelligent Multimedia, Video \& Speech Processing (ISIMP), Hong Kong, 2004.

[8] C.T. Lu, H.C. Wang, "Speech enhancement using wavelet transform with constrained thresholds", In Proc. The $3^{\text {rd }}$ International Symposium on Chinese Spoken Language Processing (ISCSLP), Taipei, Taiwan, pp. 185-188, 2002.

[9] E. Ambikairajah, G. Tattersall, A. Davis, "Wavelet Transform-based Speech Enhancement", Proc. on ICSLP, Vol. 3, 1998.

[10] V.S.R. Kumari, D.K. Devarakonda, "A Wavelet Based Denoising of Speech Signal", International Journal of Engineering Trends and Technology (IJETT), Vol. 5, No. 2, pp. 107 $115,2013$.

[11] K. Khaldi, A.O. Boudraa, A. Komaty, "Speech enhancement using empirical mode decomposition and the Teager-Kaiser energy operator", J Acoust Soc Am, Vol. 13, No. 5, pp. 451-459, 2014.

[12] T.F. Sanam, C. Shahnaz, "A semisoft thresholding method based on Teager energy operation on wavelet packet coefficients for enhancing noisy speech", EURASIP Journal on Audio, Speech and Music Processing, Springer, 2013.

[13] S. Hongo, S. Sakamoto, Y. Suzuki, "Binaural speech enhancement method by wavelet transform based on interaural level and argument differences", International Conference on Wavelet Analysis and Pattern Recognition, Xian, 2012, pp. 290-295.

[14] T. V. Pham, "Wavelet analysis for robust speech processing and applications", PHD Thesis, Graz University of Technology, 2007.

[15] I. Pinter, "Perceptual wavelet-representation of speech signals and its application to speech enhancement", Computer Speech and Language, Vol. 10, No. 1, pp. 1-22, 1996. 
[39] A. Varga, H. Steeneken, J.M. Tomlinson, D. Jones, "The Noisex-92 study on the effect of additive noise on automatic speech recognition", Technical Report. Malvern, U.K.: DRA Speech Res. Unit, 1992.

[40] H.G. Hirsch, D. Pearce, "The AURORA experimental framework for the performance evaluations of speech recognition systems under noisy conditions", Proc. ISCA ITRWASR, pp.181-188, 2000.

[41] http://pianosociety.com.

[42] Y. Lu, P.C. Loizou, "A geometric approach to spectral subtraction", Speech communication, Vol. 50, No. 6, pp. 453-466, 2008.

[43] Y. Ghanbari, M.R. Karami Mollaei, "A new approach for speech enhancement based on the adaptive thresholding of the wavelet packets", Speech communication, Vol. 48, No. 40, pp. 927-940, 2006.

[44] S. Mavaddati, S.M. Ahadi Sarkani, S. Scycdin, "Modified coherence-based dictionary learning method for speech enhancement", Signal Processing, IET, Vol. 9, No. 7, pp. 1-9, 2015.

[45] J. Benesty, Springer handbook of speech processing, Springer's publication, pp. 843-871, 2008 .

[46] J. Demsar, "Statistical comparisons of classifiers over multiple data set", The Journal of Machine Learning Research, Vol. 7, pp. 1-30, 2006.

[47] D.J. Sheskin, Handbook of Parametric and Nonparametric Statistical Procedures, 4nd ed. Boca Raton, FL: Chapman \& Hall/CRC, 2000.

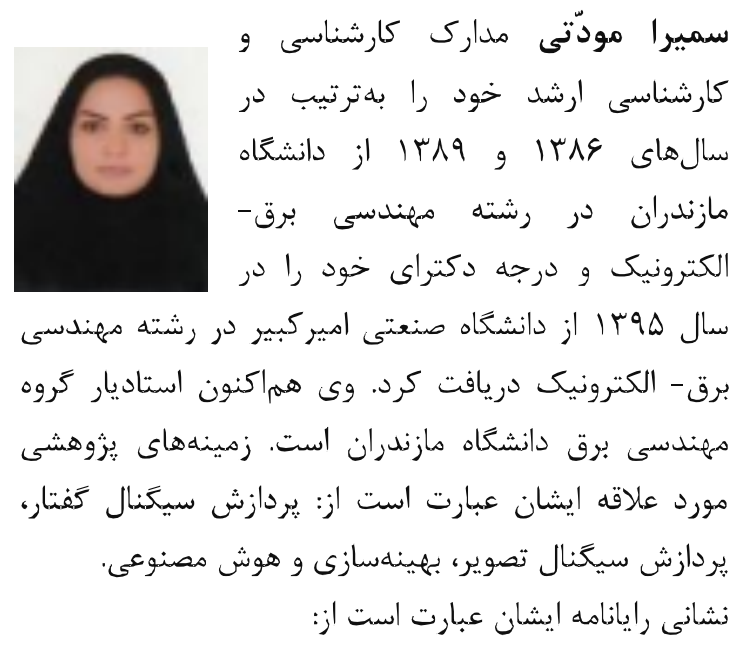

s.mavaddati@umz.ac.i
[27] S.Mavaddati, M. Ahadi, "Speech Enhancement using Adaptive Data-Based Dictionary Learning", JSDP, vol. 17 (1), pp. 99-116, 2020.

[YNA] مظفرى، رضا، مودّتى، سميرا، "ارائه روش جديد حذف

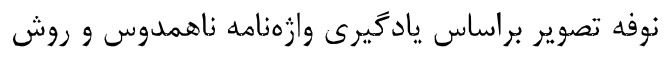

تطبيق فضا"، يردازش علائم و دادهها، جلد عاء، شماره

$$
\text { f I f }
$$

[28] R. Mozaffari, S. Mavaddati, "A Novel Image Denoising Method Based on Incoherent Dictionary Learning and Domain Adaptation Technique", JSDP, vol. 16 (4), pp.73-92. 2020.

[29] C.D. Sigg, T. Dikk, J.M. Buhmann, "Speech enhancement using generative dictionary learning", IEEE Transactions on Audio, Speech and Language Processing, Vol. 20, No.6, pp.1698-1712, 2012.

[30] B. Efron, T. Hastie, I. Johnstone, R. Tibshirani, "Least angle regression", Ann. Stat., Vol. 32, pp. 407-499, 2004.

[31] M. Aharon, M. Elad, A. Bruckstein, "K-SVD: An algorithm for designing overcomplete dictionarics for sparse representation", IEEE Trans. Signal Process, Vol. 54, No. 11, pp. 4311-4322, 2006.

[32] X. Wu, D. Yu, "Atomic Decomposition Method Based on Adaptive chirplet Dictionary", Advances in Adaptive Data Analysis, Vol. 4, pp. 1-19, 2012.

[33] J. Tropp, I. Dhillon, R.J. Heath, T. Strohmer, "Designing structural tight frames via an alternating projection method", IEEE Trans. on Information Theory, Vol. 51, No.1, pp. 188-209, 2005.

[34] M. Sustik, J. Tropp, I. Dhillon, R. Heath, "On the existence of equiangular tight frames", Linear Algebra and Its Applications, Vol. 426, No. 2, pp. 619-635, 2007.

[35] D. Liu, J. Nocedal, "On the limited memory BFGS method for large scale optimization", Math. Program, Vol. 45, pp. 503-528, 1989.

[36] S. Mavaddati, S.M. Ahadi Sarkani, S. Seyedin, "Speech enhancement using sparse dictionary learning in wavelet packet transform domain", Computer Speech and Language, Vol. 44, pp. 22-47, 2017.

[37] D.L. Donoho, "De-noising by soft-thresholding", IEEE Trans. Inf. Theory, Vol. 4, No. 3, pp. 613$627,1995$.

[38] http://www.dcs.shef.ac.uk/spandh/gridcorpus. 